\title{
Simulation-Based Optimization of a Series Hydraulic Hybrid Vehicle
}

\section{Katharina Baer}

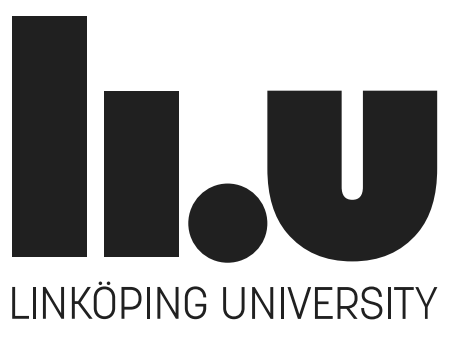

Division of Fluid and Mechatronic Systems Department of Management and Engineering Linköping University, SE-581 83 Linköping, Sweden 
Copyright (C) Katharina Baer, 2018

Simulation-Based Optimization of a Series Hydraulic Hybrid Vehicle

ISBN 978-91-7685-344-3

ISSN 0345-7524

Cover: Kevin Cools

Distributed by:

Division of Fluid and Mechatronic Systems

Department of Management and Engineering

Linköping University

SE-581 83 Linköping, Sweden

Printed in Sweden by LiU-Tryck, Linköping 2018. 


\section{To Wim}

The brick walls are there for a reason. (...) [They] are there to give us a chance to show how badly we want something. 



\section{Abstract}

H

YBRID TRANSMISSIONS are characterized by their utilization of more than one form of energy storage. They have the potential to help reduce overall fuel consumption and vehicle emissions by providing the possibility of brake energy recuperation and prime mover operation management. Electric hybrids and electric vehicle drives are nowadays ubiquitous, and mechanical energy storage in flywheel has been investigated in the past. The use of fluid power technology with a combustion engine has also been investigated since the late 1970s, and is frequently revisited.

Hydraulic hybridization is especially attractive for heavy vehicles with frequent braking and acceleration which benefit most from fluid power components' high power density, typically busses, delivery or refuse vehicles, and vehicles with existing hydraulic circuits and transmissions, such as forest and construction machinery, but have been considered for smaller vehicles as well.

Due to the characteristic discharge profile of hydraulic energy storage, special attention needs to be paid to control aspects in the design process to guarantee drivability of the vehicle. In this respect, simulation models can be of use in early design process stages for cheaper and faster evaluation of concepts and designs than physical experiments and prototyping, and to generate better understanding of the system studied. Engineering optimization aids in the systematic exploration of a given design space, to determine limits and potentials, evaluate trade-offs and potentially find unexpected solutions. In the optimization of a hydraulic hybrid transmission, the integration of component and controller design is of importance, and different strategies (sequential, iterative, bi-level and simultaneous approaches) are conceivable, with varying consequences for the implementation.

This thesis establishes a simulation-based optimization framework for a hydraulic hybrid transmission with series architecture. Component and control parameter optimization are addressed simultaneously, using a rule-based supervisory control strategy. The forward-facing dynamic simulation model at the centre of the framework is built in Hopsan, a multi-disciplinary open-source tool developed at Linköping University. The optimization is set up and conducted for an example application of an on-road light-duty truck over standard drive 
cycles. Both results from these experiments as well as the framework itself are studied and evaluated. Relevant design aspects, such as explicit design relations to be considered and performance requirements for more robust design, are identified and addressed, and the optimization problem is analysed with regard to algorithm performance and problem formulation. The final result is an optimization framework that can be adjusted for further in-depth studies, for example through the inclusion of additional components or optimization objectives, and extendable for comparative analysis of different topologies, applications and problem formulations. 


\section{Populärvetenskaplig Sammanfattning}

$\mathrm{H}_{3}$

YBRIDA TRANSMISSIONER kännetecknas av att de kan lagra energi i mer än en typ av energilager. De har potential att minska såväl total bränsleförbrukning som utsläpp hos vägfordon genom att möjliggöra återvinning av bromsenergi och optimal styrning av förbränningsmotorn. Elektriska hybrider och elfordon är idag vanligt förekommande, och mekanisk energilagring i svänghjul har tidigare undersökts. Likaså har användandet av hydraulik kombinerat med en förbränningsmotor undersökts sedan slutet av 1970-talet och återupptas ofta.

Hydraulisk hybridisering är speciellt attraktiv för tunga fordon som bromsar och accelererar ofta och som drar stor nytta av hydraulikkomponenternas höga effektdensitet. Konceptet har använts för bussar, leverans- eller sopbilar och fordon med befintliga hydraulsystem och hydrauliska transmissioner, såsom skogs- och anläggningsmaskiner, men har också beaktats för mindre fordon.

På grund av det hydrauliska energilagrets karakteristiska urladdningsprofil måste särskild uppmärksamhet ägnas åt regleraspekter under designprocessen. Detta för att garantera fordonets körbarhet. Här kan simuleringsmodeller användas i tidiga stadier för att billigare och snabbare utvärdera koncept och designer jämfört med hårdvarutester och prototyptillverkning, och för att få en bättre förståelse för det studerade systemet. Optimering kan hjälpa till med att systematiskt utforska av en viss designrymd, att synliggöra begränsningar och möjligheter, att utvärdera avvägningar och att eventuellt hitta oväntade lösningar. Vid optimering av en hydraulisk hybrid är integrationen av komponentoch reglerdesign av betydelse, och olika strategier (sekventiella, iterativa, binivå och simultana tillvägagångssätt) är möjliga med varierande konsekvenser för implementeringen.

I denna avhandling upprättas ett simuleringsbaserat ramverk för optimering av hydrauliska seriehybrider. Optimering av komponent- och reglerparametrar utförs samtidigt, med hjälp av en regelbaserad styrstrategi. Den dynamiska simuleringsmodellen i kärnan av ramverket är implementerad i Hopsan, ett 
multidisciplinärt open source-verktyg som utvecklats på Linköpings universitet. Optimeringen utförs på en lätt lastbil med standardiserade körcykler som exempelapplikation. Resultatet från såväl dessa experiment som ramverket i sig studeras och utvärderas. Relevanta designaspekter, såsom exakta designrelationer som ska beaktas och prestandakrav för en mer robust design, identifieras och adresseras och optimeringsproblemet analyseras med avseende på algoritmprestanda och problemformulering. Resultatet är ett optimeringsramverk som kan justeras för ytterligare djupgående studier, till exempel genom att inkludera ytterligare komponenter eller optimeringsmål, och utvidgas för jämförande analys av olika topologier, applikationer och problemformuleringar. 


\section{Acknowledgements}

Since I came to Linköping for the first time as an Erasmus student many years ago, life has taken many unexpected turns. Getting to write these lines, reflecting on the past years that got me to this point, is definitely not something I foresaw then. But it is a very gratifying part of the process!

First and foremost I want to thank my main supervisor Petter Krus for his initial willingness to take a chance on me, for letting me come to Sweden again and dive into the world of fluid power. Thank you for your continued support and unwavering encouragement, your guidance when needed, the freedom to find my way and the special working environment you have created at Flumes. There have been quite a few moments - the first one being offshore in Florianópolis - when I got to stop and realize how grateful I am for this very unique experience.

Liselott Ericson became my co-supervisor when things began to roll, and has been a great source of support along the way. Besides our many technical discussions, thank you for your steadfastness throughout the years, and your ability to complement everything I was experiencing with calm and resultminded focus.

My work would not have been possible without the support I received from Magnus Sethson, Robert Braun, and especially Peter Nordin concerning both the Hopsan software and the Fluster/T15 clusters - thank you for providing the foundation and infrastructure for my research.

My present and former colleagues at the Division of Fluid and Mechatronic Systems (Flumes) have kept up a friendly, inspiring, non-judgmental and extremely educational work environment for which I am very grateful. A few need to be mentioned by name for their impact on this thesis: Raghu Chaitanya and Edris Safavi (of the Division of Machine Design) were my early office mates and made the first few months so much easier. Ingo Staack, Alejandro Sobrón and Viktor Larsson were a great support throughout the final year thank you for the lengthy discussions and the encouragement. Thank you all for your friendship!

Through everything, Rita Enquist has been an absolute champion - thank you for everything, including your personal interest in evolving my Swedish! I 
would also like to mention our former neighbours, the Division of Machine Design - a great number of you have made my time a lot more fun and interesting, and have been very generous with your advice and time - thank you.

When coming to the Department of Management and Engineering (and Linköping University overall), I have appreciated immensely being able to meet people from many different disciplines and countries, and some of the friendships I have formed were what carried me through good and bad times alike. Christina, Elaine, Susan, Jenny, Sayeh and Sarah - I am so glad to have met warm, smart and strong women like you, thanks for your friendships, your support and encouragement, and for your healthy dose of patience when listening to me talking hydraulic hybrids! Manon, Mario and Tim - you have been such a reassuring constant presence during my time as PhD student, and I cannot thank you enough for lots of fun over all the years, especially exploring Linköping and Sweden, but also for providing lots of perspective when needed!

I would not have come to this particular point in my academic career without Hans Corsten, Annette Reincke, Eva Estornell-Borrull and Christian Scholler. You have all over many years provided small and big stepping stones enabling me to consider and take on the challenge of pursuing PhD studies, in Sweden, in the field of fluid power, and I want to take a moment to acknowledge that this would not have happened without you.

Moving abroad means by definition that some relationships need to go longdistance. A good friendship can survive distance no matter what, or so they say, and I am beyond grateful for all those amazing German and Dutch friends who have dealt with us dropping by occasionally, often with complicated planning involved - and who nonetheless made me feel as if I had come home, or as if I never left. My Dutch family-to-be has dealt with our country-hopping life magnificently, and never ceased to cheer me on from a distance - van harte bedankt! My German family has been unconditionally supportive throughout my entire education, and incredibly accepting of all my international activities (which may have started a trend in the family) - thank you!

Last but not least... During my first stint in Linköping, the least expected turn was a certain Dutchman entering my life, shaking it to the core, and making it better all the way since. Wim, thank you for everything - for who you are, for challenging and inspiring me, supporting me in and throughout this entire endeavour, for making sure I travel enough, and tackling life with me!

Linköping, February 2018

Katharina Baer 


\section{Abbreviations}

ARVD Average Relative Velocity Deviation

BSFC Brake Specific Fuel Consumption

EPA Environmental Protection Agency

ERI Entropy-Rate-Based Performance Index

HEV Hybrid Electric Vehicle

HHV Hydraulic Hybrid Vehicle

HWFET Highway Fuel Economy Test

ICE Internal Combustion Engine

MHV Mechanical Hybrid Vehicle

NEDC New European Driving Cycle

NYCC New York City Cycle

PSO Particle Swarm Optimization

SBO Simulation-Based Optimization

SHHV Series Hydraulic Hybrid Vehicle

SoC State-of-Charge

SUV Sport Utility Vehicle

SVD Singular Value Decomposition

TLM Transmission Line Modelling

UDDS Urban Dynamometer Driving Schedule

WLTC3 Worldwide harmonized Light vehicles Test Cycle, class 3

WOT Wide Open Throttle 


\section{Notation}

$\delta_{x, i}$

$\eta_{h m, p m}$

$\eta_{h m, p}$

$\eta_{v o l, p m}$

$\eta_{v o l, p}$

$\gamma$

$\omega_{p}$

$\omega_{i d l e}$

$\omega_{\max }$

$\omega_{p m}$

$\omega_{r e f}$

$\omega_{\text {target }}$

$\Phi_{\mathrm{FE}}$

$\Phi_{\text {IT }}$

$\tau_{a c c}$

$\varepsilon_{p}$

$\varepsilon_{p m}$

Complex-RF(P) algorithm: reflection factor

Mean specific heat capacity

$[\mathrm{J} /(\operatorname{kg} \mathrm{K})]$

Complex-RF(P) algorithm: randomization factor

$[-]$

Absolute uncertainty of parameter $i$

(unit is parameter-dependent)

Relative uncertainty in parameter $i$

Hydro-mechanical efficiency of pump/motor

Hydro-mechanical efficiency of pump

Volumetric efficiency of pump/motor

Volumetric efficiency of pump

Complex-RF(P) algorithm: forgetting factor

Break frequency for pump dynamics

$[\mathrm{rad} / \mathrm{s}]$

Engine idling speed

$[\mathrm{rad} / \mathrm{s}]$

Maximum engine speed

$[\mathrm{rad} / \mathrm{s}]$

Break frequency for pump/motor dynamics

$[\mathrm{rad} / \mathrm{s}]$

Engine reference speed

$[\mathrm{rad} / \mathrm{s}]$

Target engine speed

$[\mathrm{rad} / \mathrm{s}]$

ERI on the base of objective function evaluations (fe) [bit/fe]

ERI on the base of optimization algorithm iterations (it) [bit/it]

Accumulator time constant

$[\mathrm{s}]$

Pump displacement setting

Pump/motor displacement setting 
$\varepsilon_{x} \quad$ Parameter convergence criterion

$A_{a c c}$

Accumulator surface area

$c_{d} A$

Effective front area of vehicle

$c_{f r}$

Rolling resistance coefficient

$D_{p}$

Pump displacement volume

Pump/motor displacement volume $\left[\mathrm{m}^{3} / \mathrm{rev}\right]$

$D B_{\Delta v}$

Deadband for acceleration-based SoC limit modulation

$E_{a c c}$

Energy content of accumulator

$E_{\text {system }}$

Total energy in system

$E_{\text {vehicle }}$

Kinetic energy of vehicle

FC

Fuel consumption

$F C_{\text {start,ICE }}$ Diesel engine start-up fuel consumption

Heat transfer coefficient

$H_{x}$

Information entropy in optimization parameters (input-side entropy)

$H_{y}$

Information entropy for optimization results (output-side entropy)

Engine flywheel inertia

Gain for acceleration-based SoC limit modulation

Number of design parameters for optimization (dimensions) [-]

$N_{m}$

Number of optimization iterations or function evaluations

$N_{m, \max , \mathrm{IT}}$

Maximum number of optimization iterations

$p_{\text {high }}$

Upper static SoC pressure limit

$p_{\text {low }}$

Lower static SoC pressure limit

Split point for SoC modulation in $\left[p_{\text {low }}, p_{\text {high }}\right]$, expressed relatively to interval 
$q_{\text {ref }} \quad$ Reference flow parameter for pump/motor displacement setting reduction

$T_{a m b} \quad$ Ambient temperature

Drive cycle duration

$t_{\text {start,ICE } \quad \text { Engine start-up time }}$

$x_{i}$

Design parameter $i$

(unit is parameter-dependent) 


\section{Papers}

T

HIS THESIS IS built on the five papers appended. Each of the papers builds on its respective predecessor, especially with regard to extension and refinement of the system model used. Concerning the methodology, paper [I] explores design variations via parameter sweep. Paper [II] applies numerical design optimization to various problem formulations. These are extended further in paper [III], and supplemented with various sensitivity analyses. Based on insights gained from papers [II] and [III], paper [IV] revisits design optimization including additional requirements and considerations. Paper [V] addresses the optimization aspects in more detail. A more detailed discussion of the appended papers is included in Chapter 8.

The papers have been corrected for minor language errata. The layout of text and figures has been adapted to match the format of the thesis.

[I] K. Baer, L. Ericson, and P. Krus. "System Parameter Study for a LightWeight Series Hydraulic Hybrid Vehicle". In: Proceedings of the 8th FPNI Ph.D Symposium on Fluid Power. Lappeenranta, Finland, June 2014.

[II] K. Baer, L. Ericson, and P. Krus. "Design Study and Parameter Optimization for a Light-Weight Series Hydraulic Hybrid Vehicle". In: Proceedings of the Fourteenth Scandinavian International Conference on Fluid Power. Tampere, Finland, May 2015.

[III] K. Baer, L. Ericson, and P. Krus. "Aspects of Parameter Sensitivity for Series Hydraulic Hybrid Light-Weight Duty Vehicle Design". In: Proceedings of the ASME 2016 9th FPNI Ph.D Symposium on Fluid Power. Florianópolis, SC, Brazil, Oct. 2016.

[IV] K. Baer, L. Ericson, and P. Krus. "Framework for Simulation-Based Simultaneous System Optimization for a Series Hydraulic Hybrid Vehicle". Submitted to International Journal of Fluid Power, Sept. 2017.

[V] K. Baer, L. Ericson, and P. Krus. "Optimization Method Evaluation for Simulation-Based Control and Component Parameter Design of a Series Hydraulic Hybrid Vehicle". Submitted to Engineering Optimization, Dec. 2017. 
Katharina Baer is the main author for all publications stated above, and responsible for the work in the papers. Liselott Ericson provided early component models for the first two papers. Both co-authors provided support and feedback throughout the publication process.

\section{Additional publications}

The following papers are not included in the thesis, but contain early iterations of the thesis topic, and thus laid the foundation for papers $[\mathrm{I}]$ to $[\mathrm{V}]$.

[VI] K. Baer, L. Ericson, and P. Krus. "Modeling of a Series Hybrid Hydraulic Drivetrain for a Light-Duty Vehicle in Hopsan". In: Proceedings of The 13th Scandinavian International Conference on Fluid Power. Linköping, Sweden, June 2013.

[VII] K. Baer, L. Ericson, and P. Krus. "Component Sizing Study for a LightDuty Series Hydraulic Hybrid Vehicle in Urban Drive Cycles". In: Proceedings of the 22nd International Congress of Mechanical Engineering. Ribeirão Preto, SP, Brazil, Nov. 2013. 


\section{Contents}

1 Introduction 1

1.1 Motivation ..................... 1

1.2 Research Aim and Research Questions . . . . . . . . . . . . 2

1.3 Scope ........................ . . 3

1.4 Research Method . . . . . . . . . . . . . . . . . . 3

1.5 Research Focus and Progression in the Appended Papers ... . 4

1.6 Contributions . . . . . . . . . . . . . . . . . 6

2 Hydraulic Hybrid Transmissions $\quad 7$

2.1 (Combustion-)Hydraulic Hybrid Transmissions . . . . . . . 8

2.1.1 Principal Hydraulic Hybrid Architectures . . . . . . . 8

2.1 .2 Applications . . . . . . . . . . . . . . . 9

2.1.3 Commercial R\&D into On-Road Hydraulic Hybrid Vehicle Transmissions . . . . . . . . . . . . . . . 9

2.2 Control of Hydraulic Hybrid Transmissions _ . . . . . . . . 10

2.3 Design of Hydraulic Hybrid Transmissions . . . . . . . . . . 11

3 Modelling of a Series Hydraulic Hybrid Vehicle Transmission 15

3.1 System Modelling . . . . . . . . . . . . . . . . . . 17

3.1.1 Series Hydraulic Hybrid Vehicle System Configuration . 17

3.1.2 Main Series Hydraulic Hybrid Vehicle Components . . . 17

3.2 Control Strategy for Series Hydraulic Hybrid Vehicle . . . . . . 19

4 Framework for Simulation-Based Optimization 23

4.1 Optimization Problem Formulation . . . . . . . . . . . . . 24

4.1.1 Optimization Objective Function . . . . . . . . . . . . 24

4.1 .2 Design Parameters . . . . . . . . . . . . . . . . 25

4.1 .3 Optimization Problem . . . . . . . . . . . . . . . 26

4.2 Optimization Algorithm . . . . . . . . . . . . . . 26

4.3 Optimization Performance Evaluation $\ldots \ldots \ldots . \ldots 27$ 
5 Optimization Experiments $\quad 29$

5.1 Vehicle Application . . . . . . . . . . . . . . . . . . . . . . . . . . 29

5.2 Experiment Overview . . . . . . . . . . . . . . . . . . 32

5.2.1 Baseline Optimization Experiments . . . . . . . . . . 32

5.2.2 Variation: Drive Cycles for Optimization . . . . . . . 35

5.2.3 Variation: Problem Dimensionality for Optimization . . 38

5.2.4 Variation: Optimization Algorithms for Series Hydraulic Hybrid Design . . . . . . . . . . . . . . 40

6 Discussion $\quad 45$

7 Conclusions $\quad 49$

8 Review of Papers $\quad 51$

Appendices $\mathbf{5 5}$

A.1 Specifications of Optimization Computers . . . . . . . . 55

A.2 Component Scaling . . . . . . . . . . . . . . . . 57

A.3 System Parameter Sensitivities . . . . . . . . . . 58

$\begin{array}{ll}\text { Bibliography } & 61\end{array}$

\section{Appended Papers}

I System Parameter Study for a Light-Weight Series Hydraulic Hybrid Vehicle

II Design Study and Parameter Optimization for a LightWeight Series Hydraulic Hybrid Vehicle

III Aspects of Parameter Sensitivity for Series Hydraulic Hybrid Light-Weight Duty Vehicle Design

IV Framework for Simulation-Based Simultaneous System Optimization for a Series Hydraulic Hybrid Vehicle

V Optimization Method Evaluation for Simulation-Based Control and Component Parameter Design of a Series Hydraulic Hybrid Vehicle 


\section{1 \\ Introduction}

I

$I_{N}$ THE QUEST to address scarce fossil resources and legal limitations on greenhouse gas emissions, both on-road and off-road vehicle application manufacturers and users look among other things towards hybridization of existing transmissions as a possible solution. Hybridization combines two or more forms of energy storage and accompanying power converters. For transmissions containing a combustion engine, hybridization adds the potential for energy recuperation and operating point modulation. Electric hybrids are ubiquitous, especially for on-road vehicles, but are also receiving attention for off-road applications, and potentially serve as an intermediate stage towards purely electric drivetrains. Hydraulic hybrid transmissions rely on a prime mover due to their low energy density. Their benefits, however, lie in their high power density, making them especially attractive for heavy loads with frequent power transients. Hydraulic hybridization is also of interest for off-road vehicles and machinery with existing hydraulic circuits, and hydraulic energy storage components are characterized by their robustness and long service life [1].

\subsection{Motivation}

Electric and hydraulic energy storage differ among other things in terms of their charge and discharge behaviour: unlike their electric counterpart's (battery's) voltage, a hydraulic storage component's (accumulator's) pressure and thus its potential vary greatly with its State-of-Charge (SoC). This results in limited, SoC-dependent torque and thus performance. For the design of Hydraulic Hybrid Vehicle (HHV) transmissions this can pose a challenge as the instantaneously available power from the hydraulic accumulator fluctuates. Through appropriate control of the system an available performance minimum can be maintained.

In order to optimally utilize the accumulator's high power density, all com- 
ponents of the transmission must be properly dimensioned according to the load profile for which the transmission is specified. Traditionally, the component sizing of vehicle transmissions is conducted in a heuristic process primarily aiming to achieve maximum performance requirements [2]. Hydraulic hybrid transmissions pose a more complex problem due to the control problem of the combination of different power sources (like any hybrid transmission), the inclusion of accumulators' discharge characteristics, and component scaling affecting relevant component and system parameters.

One way of addressing these challenges is to evaluate designs using computational tools. Simulation models of varying degrees of detail can serve to predict relevant performance characteristics. Furthermore, numerical optimization provides the option to systematically explore a large design space. Their integration (see e.g. $[3,4]$ ) is useful to optimize systems while taking transient system behaviour into account. Depending on the modelling detail, this can lead to high computational loads, thus requiring efficient optimization methods for satisfactory performance.

\subsection{Research Aim and Research Questions}

Overall, this thesis aims to explore the use of Simulation-Based Optimization (SBO) in the design process for a Hydraulic Hybrid Vehicle transmission. The goal is to develop a framework for the SBO, including a simulation model of the system and an optimization routine, and study a number of its relevant aspects in the process. More specifically, four research questions are formulated for this thesis.

When designing a hydraulic hybrid vehicle, a large design space needs to be explored. This can become laborious and expensive if studied on a physical system.

RQ1: How can computational tools be used to study the feasibility of HHV transmissions?

As a representation of the physical vehicle transmission, a simulation model for a series hydraulic hybrid transmission is developed.

RQ2: What aspects of the system need to be modelled and studied in the context of SBO?

The more characteristics of the transmission are to be included in the model, the computationally heavier it becomes. This then propagates further into the framework for design optimization.

RQ3: When using complex, i.e. computationally heavy, models, how can SBO be used and improved upon? 
In an iterative process, solutions generated by the optimization framework can, next to the vehicle design specifications, yield insights into the suitability of both simulation model and optimization routine for the design task.

RQ4: How can the results obtained through SBO be analysed and used to further improve the framework?

\subsection{Scope}

The experiments conducted target a specific on-road vehicle application with a particular system architecture to illustrate how the SBO framework can be used in an early design phase. Consequently, the simulation model also employs a number of simplifying modelling assumptions. The control strategy does not claim global optimality, but aims to provide robust system operation. From the multitude of conceivable and relevant objectives, the optimization problem formulation focuses on the fuel economy and driveability of the vehicle.

The model in its entirety has not been validated against a similar physical system; loss models for the main hydraulic components are, however, based on available measurements. Furthermore, the simulation model at the centre of the SBO-approach can be generalized and extended to address varied design and optimization problems, and modified to include alternative component data.

\subsection{Research Method}

The work in this thesis consisted of modelling and simulation of a Series Hydraulic Hybrid Vehicle (SHHV) transmission, the setup and execution of design optimization experiments and the subsequent analysis of the results obtained.

The mathematical model set up is based on well-established theory for the system components. Hydraulic component efficiency data were obtained experimentally, although not specifically for the work presented here. Simulation models, however, provide by definition only a simplified representation of a physical system. Consequently, they are typically used in conjunction with real-life experiments for validation and verification (see the methodology described in [5]). While the thesis focuses on the use of simulation models without equivalent physical system representation (for validation), their applicability is nonetheless evaluated within an iterative process through analysis of the results obtained (verification) (see [6] for an overview of exact definitions). In this context, different simulation model iterations serve as working hypotheses towards a model suitable for SBO of an HHV. Suitable refers in this context to capturing the most relevant aspects of the system in question, subject to the stated limitations.

The progression of the body of work itself in this thesis also illustrates an iterative process on a higher level. With the ulterior goal of a workable framework for SBO of an $\mathrm{HHV}$ transmission, results from $\mathrm{SBO}$ of the respective 


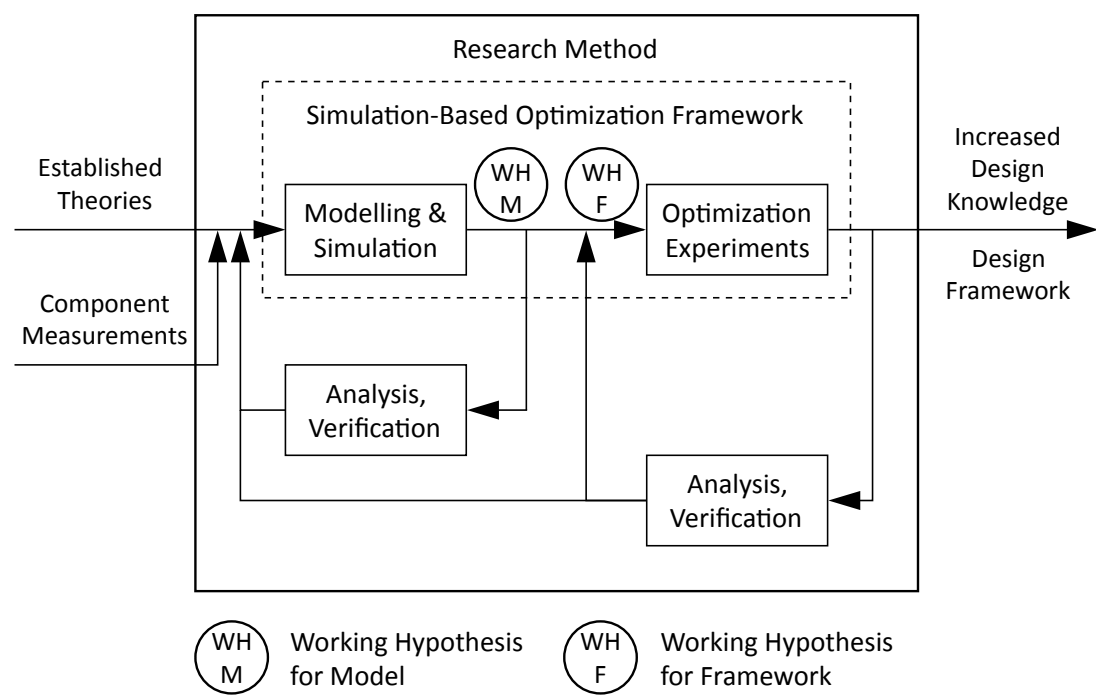

Figure 1.1 Research method (based on [5] in combination with [7])

simulation model iteration are analysed to gain further insight into the corresponding capabilities and limitations of the current SBO framework working hypotheses (see Figure 1.1 for the entire process). This kind of iterative process can be likened to Suh's [7] feedback loop of design synthesis and analysis.

\subsection{Research Focus and Progression in the Appen- ded Papers}

This thesis is based on five research papers, $[\mathrm{I}]-[\mathrm{V}]$, which were published in their numeric order, and preceded by papers [VI] and [VII]. Figure 1.2 illustrates their general relationship with respect to major SBO framework development stages. The papers in the first stage, including Paper [I], are concerned with pre-optimization simulation model development and limited design parameter studies. In the first optimization stage, experiments are conducted with a focus on optimizing transmission designs for specific usage profiles (drive cycles) with differing characteristics. Paper [III] thereby analyses the optimization results' robustness, and helped identify possibilities to improve on both the optimization framework in general and specifically the simulation model in approaching stage 3 . The updated model is presented in paper [IV], and paper $[\mathrm{V}]$ studies a number of higher-level aspects of the optimization framework. 
Each paper in itself contains updated working hypotheses for both the simulation model and the design framework, and focuses on different aspects in the analysis of the results obtained (Figure 1.3). As such, they all contribute to the more general RQ1, and largely to RQ2. RQ3 is closely connected to efficient optimization, and while the use of advanced computational infrastructure from paper [III] on facilitates larger experiment volumes, this aspect is most prominently addressed in paper $[\mathrm{V}]$. Focus on the analysis of optimization results (RQ4) includes sensitivity analyses (especially in paper [III], but also in its successors) and the study of the optimization performance with special attention to the quality of results obtained (paper $[\mathrm{V}]$ ).

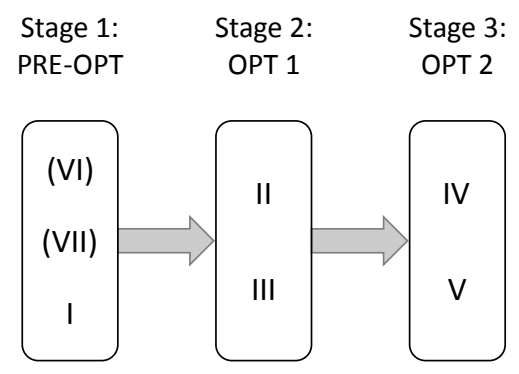

Figure 1.2 Organization and progression of research publications (OPT: optimization)

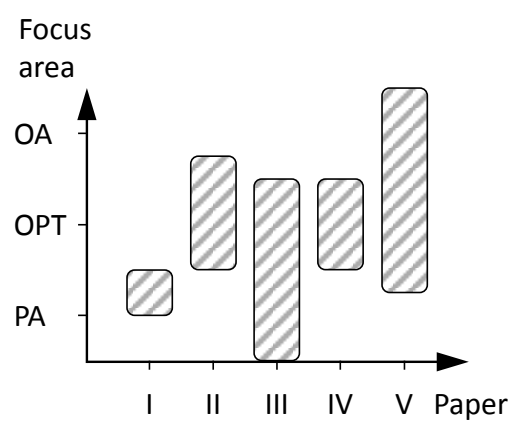

Figure 1.3 Focus in research papers (PA: parameter analysis, OPT: optimization, OA: optimization and framework analysis) 


\subsection{Contributions}

The main contributions of the work presented in this thesis are

- the development of a simulation-based optimization framework, using a forward-facing, dynamic system model for simultaneous component and control design for a series hydraulic hybrid vehicle transmission,

- the study of the framework with regard to not only modelled system, but also the optimization problem, including for example the formulation of test cases and the parameterization of the system, and

- the evaluation of examples of non-gradient-based optimization methods for simulation-based optimization of complex systems in both single- and multi-core architectures.

In support of these, two detailed aspects have been addressed.

- The model utilizes a rule-based control strategy, which can result in harsh transients. Considerations for the modification of a rule-based control strategy are outlined. The effect of their inclusion in the design optimization problem is studied.

- The entropy-rate-based performance index for optimization is extended to gain independence from a binary success criterion. An equivalent to the information entropy in design parameters is defined to capture how well multiple optimizations converge on a (perceived) globally optimal solution. Both measures aid in evaluating an optimization algorithm's performance for noisy objective functions. 


\section{2 \\ Hydraulic Hybrid Transmissions}

$\mathrm{H}$

YBRID TRANSMISSION TECHNOLOGIES aim to improve fuel economy and reduce transmission emissions through intelligent use and combination of several sources of energy and corresponding power converters. This can be achieved through power decoupling for more efficient operation as well as the recuperation of kinetic or potential energy instead of having it dissipate as heat. Hybrids are typically classified according to their energy storage medium, the degree of hybridization, and the integration of different technologies.

- Vehicular applications typically consider an Internal Combustion Engine (ICE) as prime mover. Based on the secondary technology used, Hybrid Electric Vehicles (HEVs) using batteries or super-capacitors, HHVs with hydraulic accumulators or Mechanical Hybrid Vehicles (MHVs) with mechanical flywheels are distinguished. Less commonly found are electrichydraulic solutions (especially in forklift applications, e.g. [8, 9], but also for other vehicles, e.g. $[10,11])$.

- Hybrid drives can range from micro- to range-extending hybrids. Between these extremes, more commonly found are mild and full hybrids: while mild hybrids offer limited energy recuperation and consequently provide boost power for the prime mover, e.g. at launch, full hybrids can additionally operate, at least to a limited extent, solely on the secondary energy source [2].

- In principle, a secondary technology can be implemented between prime mover and application, forming a series hybrid, or in a parallel, additive arrangement as a parallel hybrid. So-called power-split configurations combine a series hybrid transmission with a parallel (mechanical) transmission path, and may be seen as a blend of the other two. 
Hereafter, the focus will be on hydraulic hybrid transmissions, with occasional reference to HEVs where beneficial.

\section{1 (Combustion-)Hydraulic Hybrid Transmissions}

Hydraulic storage components (accumulators) are characterized by a higher power density and a lower energy density than their electric counterparts $[1,12]$. For vehicle applications this makes a purely hydraulic or range extending hybrid infeasible, but becomes attractive for highly transient (high brake frequency) and high power applications. Additional benefits are seen in the availability, robustness and cost of components $[13,1,14]$.

\subsubsection{Principal Hydraulic Hybrid Architectures}

Figure 2.1 illustrates the principal hydraulic hybrid transmission architectures, wherein numerous configuration variants are possible in return. Each of the basic architectures offers specific advantages: with a continuously variable hydraulic hybrid transmission connected in series between ICE and vehicle, the engine's operation can be entirely decoupled from the drive side to realize more efficient operation. The parallel component arrangement maintains the highly efficient mechanical transmission path, making it also more attractive for retrofitting existing drivelines, and uses hydraulically stored energy for boosting the engine or when power requirements are extremely low. The power-split architecture is more complex due additional couplings, typically through planetary gears, and aims to combine both the series hybrid's ICE decoupling and the parallel hybrid's mechanical efficiency advantages.

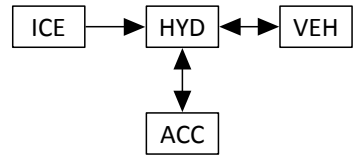

Series Hydraulic Hybrid

ICE Internal Combustion Engine

HYD Hydrostatic Transmission

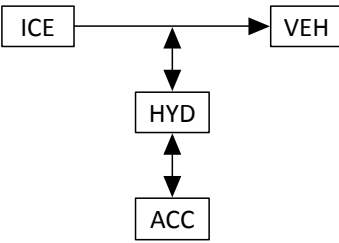

Parallel Hydraulic Hybrid

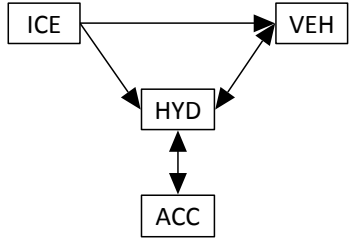

Power-Split Hydraulic Hybrid

Figure 2.1 Principal HHV transmission architectures [VII] 


\subsubsection{Applications}

Hydraulic hybrid transmissions have been considered for a multitude of onand off-road applications. Pourmovahed [15] provided an overview of early activities, including both simulation studies and prototype development up to the mid-1980s, which was later extended slightly by Stecki and Matheson [16].

Based on the technology characteristics, hydraulic hybridization for brake energy recuperation is of greatest interest for heavy vehicles with frequent braking and (re-)acceleration driving events. Prime examples amongst on-road vehicles are city buses, refuse trucks and (local) delivery vehicles [1]. Indeed, early research and development, at least partially motivated by the 1970s oil crises, was focused on city buses, such as for example the MAN Hydro-Bus [17], the Cumulo Brake Energy Drive developed and tested for buses and its hydrostatic successor $[18,19]$, studies at the Technical University of Denmark (cf. [20] with further reporting in [21]), and Mitsubishi's buses with brake energy recuperation [22]. Passenger vehicles have nonetheless been subject to research activity (cf. for example [23, 24] for early examples). Based on their increased kerb weight, Sport Utility Vehicles (SUVs) are assumed to lend themselves more easily to hybridization [25, 26]. Off-road applications considered include medium- and heavy-duty military vehicles [27, 28, 29].

A second group of mobile systems of interest for hybridization is identified where an existing hydraulic system meets energy recuperation potential, often in off-road machinery such as construction and forest machinery and in material handling applications. Many of these can also benefit from the possibility of potential energy recuperation. Such machines include wheel loaders and excavators (cf. e.g. [30, 31]), forest machinery (cf. Thiebes [12] for some developments), and material handling machines (cf. for example [32, 33, 34]).

\subsubsection{Commercial R\&D into On-Road Hydraulic Hybrid Vehi- cle Transmissions}

In the past two decades, the exploration of hydraulic hybrid solutions regained attention with increased focus on fuel economy due to price surges and the limitation of greenhouse gas emissions. A substantial body of work was completed at the United States Environmental Protection Agency (EPA) with several industrial partners, presenting demonstrators for initially lighter vehicles [26] as well as commercial delivery vehicles and medium-sized bus applications [35].

- The Hydraulic Regenerative Braking (HRB) system by Bosch-Rexroth is available as a parallel add-on system for retrofitting mechanical transmissions or as an extension to existing hydrostatic transmissions (as found for example in lift trucks) into series hydraulic hybrid transmissions [1, 36]. The company was also involved in the development of the Peugeot Group's Hybrid Air, a power-split passenger vehicle concept [37], which has since been put on hold [38]. 
- With the Hydraulic Launch Assist (HLA) Eaton [39] offered a since discontinued [40] parallel hydraulic hybrid solution for heavy vehicles such as refuse trucks. They have also launched a series hydraulic hybrid parcel delivery vehicle [41] developed in collaboration with EPA and other partners.

- Ford had been involved with EPA in the development of hydraulic hybrid transmissions for a light truck [35, 26], with a parallel architecture, and SUVs (see [26] for a series hybrid, and [25] for a parallel hybrid, referred to as Hydraulic Power Assist). Recently, Ford partnered with Lightning Hybrids [42] to provide parallel hydraulic hybrid solutions targeted at delivery vans and shuttle buses.

- Parker Hannifin's RunWise system [43] follows in the tradition of the Cumulo hydraulic bus drives. Designated an 'advanced series' hybrid architecture, it complements a series hydraulic hybrid transmission with a more efficient direct mechanical drive at higher vehicle speeds.

Two manufacturers of novel, highly-efficient hydraulic machine concepts, Artemis Intelligent Power Ltd and Innas B.V., have studied HHV applications with their products. Artemis tested both a series hybrid transmission for a mid-size luxury car [44] and parallel hybrid bus transmissions [44, 45]. Innas [46] presented a case study for a passenger car.

\subsection{Control of Hydraulic Hybrid Transmissions}

Whether the potential of hybridization can be fully or sufficiently realized depends not only on feasible applications [1], efficient components [35] and their appropriate configuration, but also on the operation strategy for the hybrid system (power- or energy management strategy). This has in recent years become a focus area for research activities, and control concepts for HEVs are often adapted for and applied to their hydraulic equivalents. Different aspects need to be addressed: with multiple power sources available, it needs to be determined how a vehicle's power demand is to be met in the so-called supervisory control strategy. For the components and subsystems of components of the transmission, an additional lower-level control determines the individual operating points.

Early HHV studies and concepts relied on engineering intuition to derive implementable control strategies or look-up tables for control signals computed offline. They include considerations of the recuperable brake energy and its reuse as well as efficient and non-transient component operation, subject to the instantaneous power demand (cf. e.g. [20, 47, 24, 22]). Nowadays, increased computational power both online and offline has led to a multitude of control approaches, which can be classified (for example) based on the optimality of the control approach and the control and prediction horizon [48, 49]. Globally 
optimal control sequences can be obtained for fully known driving missions, e.g. through Dynamic Programming (DP) [48]. This approach comes at the cost of a high computational burden, and the a priori information required is typically not implementable in real-world applications. It can, however, serve as a benchmark for alternative approaches and to evaluate the maximum potential of a given transmission. In contrast, heuristics, including both rule-based and fuzzy-logic approaches (cf. [49]), yield implementable, yet suboptimal results (cf. e.g. [13, 50]). They can, however, be tuned to closely follow optimal control trajectories.

Other approaches include instantaneous optimization through for example the Equivalent Consumption Minimisation strategy (cf. e.g. [51] for an HHV) which addresses the hybrid power split with a varying information horizon, and methods anticipating future power requirements such as Model-Predictive Control or stochastics-based approaches (cf. e.g. [52] for the latter two strategies; [48, 49] provide extensive overviews of control strategies of HEVs and both HEVs and HHVs, respectively).

\subsection{Design of Hydraulic Hybrid Transmissions}

Vehicle transmission components are typically dimensioned for their properties to meet maximum performance requirements. This approach is also applied to hydro-mechanical and hydraulic hybrid transmissions (see e.g. [29], and in the context of preliminary sizing in [53]). In [54], however, a need for sizing for sufficient power at low pressure, which leads to large systems, is raised. Different approaches for the sizing of the hydraulic accumulator can also be found, aiming for example to recuperate all or most of the vehicle's kinetic energy at maximum speed [29], or to capture a sufficient proportion of the total braking energy during typical driving [55].

Much of the recent research on HHVs focuses on establishing an optimal control benchmark for a given system and emulating it with real-time implementable control schemes (cf. e.g. [56]). Filipi et al. [28], however, point out the interdependencies between design and control parameters as well as the usage profile of an application for a concept evaluation.

To address both plant and controller, optimization strategies can be classified as sequential, iterative, bi-level or simultaneous approaches $[57,58]$. Silvas et al. [59] provide an extensive overview of optimization frameworks for HEVs for a wide range of applications. They also point out that these examples typically study a fixed topology, and focus on component sizing and control design.

Filipi et al. [28] present a sequential optimization procedure with iterative elements for a parallel hydraulic hybrid heavy truck transmission. Initially, the transmission's components are optimized for fuel economy subject to performance constraints via multi-start sequential quadratic programming. The control is then adjusted relative to a dynamic programming benchmark, before repeating the component sizing for the new control rules. The possibility 
to repeat the process with an entirely new system configuration should the fuel economy target not be met is indicated. Similarly, Kim [50] conducted optimization experiments for a light truck in a sequential fashion, first optimizing the design for different topologies including a rule-based control strategy. Optimal power management was obtained via deterministic and stochastic dynamic programming for a benchmark and an implementable control approach, respectively.

Other approaches have been presented by [60, 61, 62, 63, 64, 65, 66, 67, 68]. Several of these address a limited number of hydraulic hybrid transmission components in order to implement optimal control.

Both [60] and [61] optimize HHVs, series and parallel, respectively, with genetic algorithms, in [60] in a modified form. The optimization problems address five and six parameters, respectively. A number of feasibility conditions are formulated and implemented as gene limitations as penalty to the objective function. Four different objectives, regenerative capability, acceleration performance as well as vehicle mass and component costs, are combined with different focus targets for the optimization.

In $[62,63]$, another variant of a genetic algorithm is used for the multiobjective optimization of a series hydraulic hybrid vehicle. [62] considers one parameter to size engine and accumulator, and control parameters enabling different modes of operation of the transmission. In [63], accumulator volume and pre-charge pressure are optimized in bi-level procedure which includes the derivation of the system's optimal control through dynamic programming.

For a power-split hydraulic hybrid transmission, the sizing and control strategy development in [66] derives an optimal control strategy and follows up with component resizing of hydraulic machines and gear ratios of the planetary differential for performance requirements imposed by standard drive cycles. A bi-level design optimization approach is realized in [64], including the same component parameters. After evaluating the feasibility of a proposed design with regard to driveability requirements, a reduced complexity control optimization problem is solved. Designs are derived for different power-split architectures. A constraint on the accumulator capacity is only addressed as a post-optimization consideration. With a similar procedure, different hydraulic hybrid architectures (Figure 2.1) are optimized [65] for a passenger vehicle, each with single and again with two gears. The subsequent analysis including an accumulator size limitation is coupled with dynamic programming for optimal control.

Similarly to [64], different power-split configurations with two planetary gears are considered in [67] for a hydraulic hybrid delivery truck. The methodology includes the elimination of candidate configurations, and then iteratively explores possible planetary gear ratios concerning mechanical feasibility and fuel consumption through optimal control for simplified driving schedules.

Another optimization study for power-split hydraulic hybrid buses [68] also explores different configurations for the transmission. The hydraulic components' sizing is not part of the sizing study. Viable design candidates are iden- 
tified and parameterized considering a non-hybrid hydro-mechanical transmission, and evaluated with an optimal control strategy obtained through dynamic programming.

A comparative study of the different system and control optimization approaches was conducted by Uebel [53] for a parallel hydraulic hybrid wheel loader transmission. Limited to three component-related parameters, dynamic programming is used for control optimization in the bi-level and iterative approaches, while sequential and simultaneous strategy are conducted with different simple rule-based control schemes. The bi-level optimization with optimal control was found to result in the best solution within an acceptable time. In the context of the particular design problem, however, rule-based control approaches gave promising results, indicating their usefulness for similar, more complex problems. 


\title{
3 \\ Modelling of a Series Hydraulic Hybrid Vehicle Transmission
}

\begin{abstract}
A
$\mathrm{A}_{\mathrm{T}}$ THE CORE of the SBO framework to be developed stands a simulation model of the system studied. Mathematical models have been used ever since early research into HHV drivetrains was conducted (some examples are listed in [15]). They differ among other things with regard to the level of detail as well as the tool and its underlying simulation principle. The latter distinguishes between backward- or forward-facing models [69]: in the backward-facing approach, a desired vehicle performance, e.g. over a given velocity profile, is translated into corresponding power requirements to be delivered by the transmission, utilizing efficiency and loss maps for the components. No control signals are required. In contrast, forward-facing models contain a driver representation, components are operated based on control inputs and sufficient vehicle performance is not guaranteed. Backward-facing models can typically be simulated quicker, while the forward-facing approach can amongst others capture system dynamics and the actual vehicle performance and the effect of a control strategy $[69,70]$.

Common simulation software products to model in particular HHV transmissions include Matlab/Simulink [71], Advisor [72, 69, 73, 74], an analysis-focused tool based on the former, which was developed by the National Renewable Energy Laboratory, and Amesim [75], a commercial software for modelling multi-domain systems. Here, the latest generation of Hopsan is used [76, 77], a simulation tool developed at Linköping University since the late 1970s. While originally intended for the modelling, control and simulation of fluid power
\end{abstract}




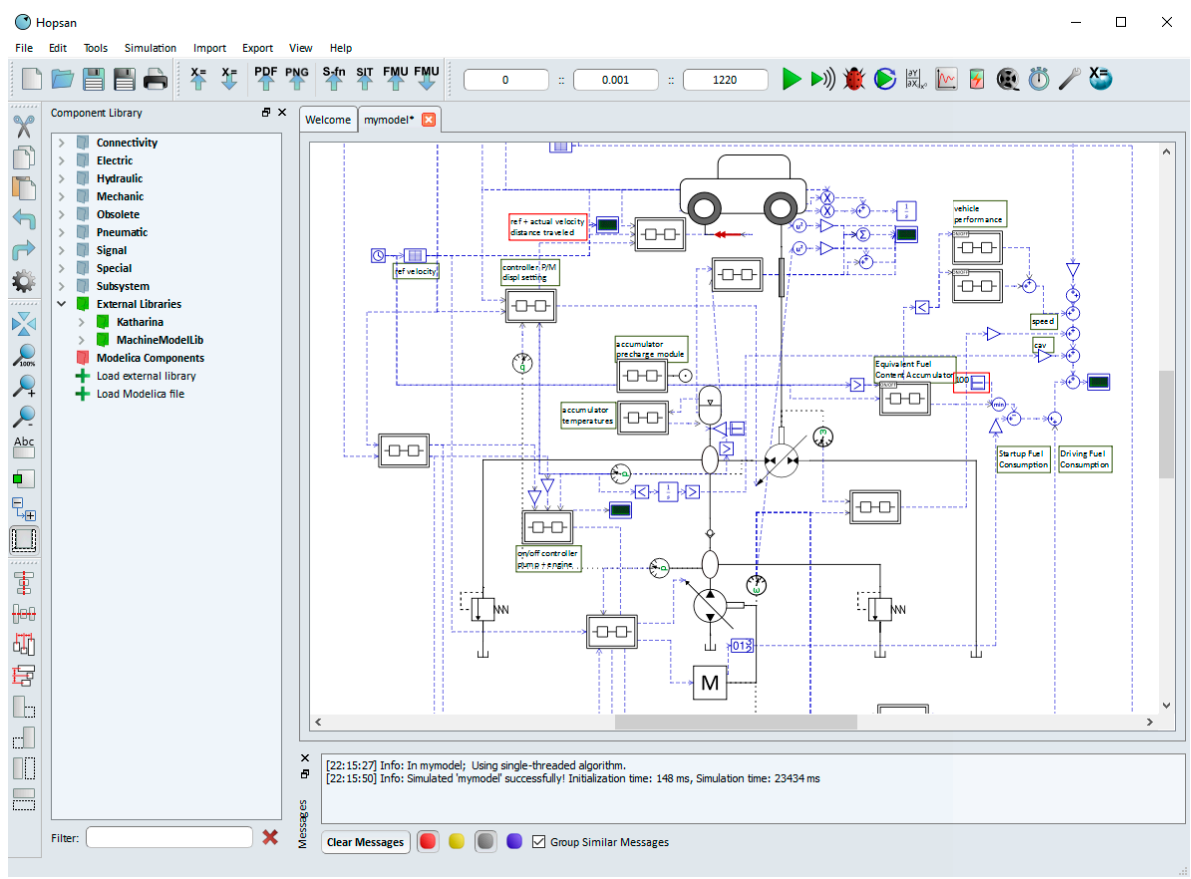

Figure 3.1 Hopsan graphical user interface with an example SHHV simulation model

systems, it also contains component libraries for multi-domain modelling and allows users to customize and develop own components. For the particular SBO application at hand, Hopsan offers some useful features, such as the ability to use it with both a graphical user interface (see Figure 3.1) and with a command line interface. Furthermore, the software is freely available, and thus independent of licensing limitations for high-volume parallel experimentation. Dynamic models in Hopsan are typically one-dimensional and apply the forward-facing simulation principle. These kinds of models can offer better understanding of the physical system than their backward-facing counterparts $[70,73]$, but require smaller simulation time steps. In principle, the use of Transmission Line Modelling (TLM) [78] in Hopsan should, however, allow for increased simulation performance on multi-core processors [79]; this has not been analysed or targeted within the scope of this thesis.

As discussed in Chapter 1, the development of the simulation model was an ongoing, iterative process over the course of the work presented in this thesis. In the following, the model's latest iteration is described (cf. also paper [IV] for additional details). 


\subsection{System Modelling}

In the case of the hydraulic hybrid transmission to be modelled here the series hybrid architecture was selected based on it containing a complete hydrostatic transmission, full decoupling of ICE and vehicle and the possibility to model the transmission without a focus on complex mechanical gearing (e.g. planetary gearing and the associated kinematics, see e.g. [64]). SHHVs have been studied frequently, and numerous variations of the basic topology can be found, such as through the addition of multi-speed mechanical gearboxes between hydraulic transmission and vehicle (see e.g. [50]), or the combination of multiple, not necessarily equally sized pump/motor components in order to realize higher power outtake speed and power as well as $4 \times 4$-operation and to increase operational flexibility in highly efficient full displacement operation (see e.g. $[80,46])$. System layouts may also offer the possibility of direct hydrostatic drive by disconnecting the hydraulic energy storage via a shut-off valve.

\subsubsection{Series Hydraulic Hybrid Vehicle System Configuration}

The system studied (cf. Figure 3.2) consists of a hydrostatic hybrid transmission, where the pump is driven by a diesel engine and one pump/motor drives the vehicle (or is driven by it during braking). The hydraulic system modelled as an open circuit system (see [81] for a discussion of open vs. closed circuit solutions). The accumulator is permanently connected to the system, and no gearing beyond the final drive ratio is considered, with the aim of reducing the number of control decisions needed. The system contains two pressure relief valves to protect it from excessive pressure. For the vehicle, a simple friction brake is modelled which provides additional brake torque if the hydraulic system's brake capacity is exhausted. Connecting elements in the system, such as hydraulic volumes and a mechanical link between hydraulic pump/motor and vehicle, need to be included due to Hopsan's underlying TLM method; they are parameterized to affect the system as little as possible, but are otherwise addressed only in a comprehensive analysis briefly discussed in paper [III], where they showed limited impact.

In the current layout, neither height profiles to study the vehicle's climbing performance (gradeability) nor reverse driving are modelled.

\subsubsection{Main Series Hydraulic Hybrid Vehicle Components}

The components of the SHHV transmission are modelled with lumped parameters. The vehicle model is one-dimensional and consider aerodynamic drag and road friction load. The hydraulic machines' dynamics are approximated with a first order low-pass filter. Efficiencies for the hydraulic axial piston machines are captured through steady-state efficiency models [82] based on previous measurements for an in-line pump and a bent-axis motor. For the pumping mode of the pump/motor, the measured pump efficiency is assumed, 


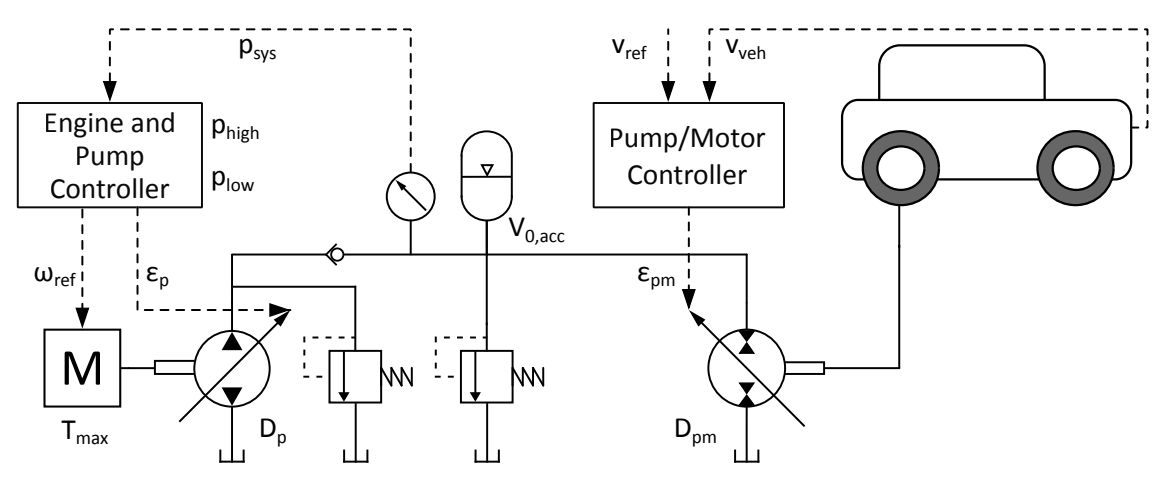

Figure 3.2 Basic system layout including controllers [V]

underestimating the actual efficiency. The accumulator gas is modelled with the Benedict-Webb-Rubin equation of state (see for example [83]; alternatives include the assumption of a polytropic process (e.g. in [84]) or the Soave modification of the Redlich-Kwong equation of state [85, 86]) with nitrogen coefficients from [87]. The accumulator's time constant for its heat exchange with the environment is based on the measurements in [8] for a bladder accumulator.

The component for the combustion engine in the transmission is highly simplified, and abandons the forward-facing modelling principle to some degree: the component is a speed-controlled torque source, considering combustion dynamics according to [88], but no further details like turbocharger or starter (see e.g. [89, 90] for more complex thermodynamic models). Efficiency considerations are captured through a Brake Specific Fuel Consumption (BSFC)-map. As the modelled series hybrid technology is of interest for engine decoupling that possibly includes an on/off control strategy, a time delay for engine startups of $0.5 \mathrm{~s}$ is modelled (see also [50]). Engine starts powered by the hydraulic system are not considered.

For a number of system parameters (such as rolling friction coefficient, aerodynamic drag coefficient, and thermodynamic constants in the accumulator model) constant values are assumed where in reality varying degrees of variability can be expected. It should also be noted that oil temperature is currently not modelled in Hopsan, and consequently heat exchange between the accumulator's oil and gas is ignored.

In order to use the model in sizing studies, the effect of component size variations on component and system properties needs to be taken into account. The most important property to consider is the additional mass of the hydraulic hybrid system, which can be offset somewhat if downsizing (or 'right-sizing' [12]) of the ICE is considered. Other scaled physical properties include the ro- 
tational inertia and speed limitations of the hydraulic machines and the surface area of the hydraulic accumulator.

For the hydraulic components, various manufacturers' component data for pressures up to $45 \mathrm{MPa}$ were evaluated. For component scaling, the Singular Value Decomposition (SVD) method can be applied to identify impact-full independent variables for datasets, which can, but do not necessarily correlate with physically equivalent properties [91]. Due to the limited pressure range and focus on single component types, SVD indicated that the data were dominated by one variable which could be reformulated to what is commonly referred to as respective component size (the machine's displacement volume or the accumulator's effective volume; see Appendix A.2 for an illustration of the scaling relationships derived from component data). The relationship between hydraulic machine speed and volumetric displacement corresponds to those found in $[92,93]$. While no oil reservoir or low-pressure accumulator is modelled, the weight of a second accumulator is considered. It should also be noted that due to the non-existence of appropriate data for mass-manufactured pump/motors, the component's scaling is based on that of a bent-axis motor, considering the more complex over-centre design through a mass surcharge. The accumulator time constant $\tau_{a c c}$ (eq. 3.1) can be expressed as a function of the nitrogen mass $m_{\text {gas }}$, the mean value of the specific heat of nitrogen $\bar{c}_{v}$, the heat transfer coefficient $h$ and the surrounding accumulator surface area $A_{a c c}$.

$$
\tau_{a c c}=\frac{m_{g a s} \bar{c}_{v}}{h A_{a c c}}
$$

While assuming constant thermodynamic coefficients and scaling $A_{a c c}$, the nitrogen mass is estimated based on the accumulator pre-charge pressure and size using the Beattie-Bridgeman equation due to implementation constraints. The limited temperature and pressure range for the equation's validity [94, 95] are considered acceptable for accumulator pre-charge conditions.

For the diesel engine, a constant speed range is assumed, and the BSFC-map scaled linearly. Assanis et al. [96] point out that this may yield inaccurate results, but observe a limited impact in an optimization study. The engine mass is estimated based on data from [74]; the inertia of moving parts from [97] is scaled based on geometric relationships and lumped together with an additional flywheel inertia on the hydraulic pump.

\subsection{Control Strategy for Series Hydraulic Hybrid Vehicle}

In order to obtain an implementable, robust control scheme for the SHHV transmission, a target of optimality was abandoned for a rule-based control strategy. The basic, supervisory control principle is similar to the thermostatic control principle in [98]: ICE and pump are operated to charge the system if the 
accumulator SoC falls below a pre-determined target level in order to maintain a power reserve. To prevent excessively transient operation and overly frequent engine starts, a SoC-deadband is defined. The SoC is thereby interpreted pressure-based. In [98], the engine power out-take is modulated between a target level and maximum rated power based on the current system SoC. Due to the prevalent engine component model, the equivalently adapted reference signal is instead the targeted operating speed.

For the pump displacement setting, initially maximum setting is targeted unless it would cause the engine to stall otherwise. The limitation can be further adjusted to target fuel minimal operation in transient between reference engine speed levels. The pump/motor displacement is set through a PI-controller based on targeted and current vehicle speed.

A number of modifications to the basic control concept in paper [I] have been implemented to incorporate fuel economy-based considerations and to achieve smoother control and improved driveability. One major motivation is that the upper SoC pressure level can pose a limit on kinetic energy recuperable into the accumulator. In an ideal, i.e. loss-free, hybrid system with both sufficiently energy density of the energy storage component and power density of power transmitting component for brake events, the total energy $E_{\text {system }} \approx$ $E_{\text {vehicle }}+E_{\text {accumulator }}$ should be constant.

- In the basic control scheme, two target pressure levels, $p_{\text {high }}$ and $p_{\text {low }}$, describe statically the SoC deadband and operating limits triggering the charge of the system through ICE and pump. Considering the increased recuperable kinetic energy, $p_{\text {high }}$ can be lowered with higher vehicle speed. At the same time, an increase in $p_{\text {low }}$ provides more performance reserve.

To improve the responsiveness of the ICE, engine stops are abandoned in favour of idling if not charging the system above the vehicle reference speed $v_{m o d, \text { ICE }} \cdot v_{m o d, \text { ICE }}$ also marks the beginning of the reference-speeddependent dynamic SoC modulation. Additional describing parameters include the upper speed limit, $v_{\max , \mathrm{SoC}}$, as well as the split point for modulation between $p_{\text {low }}$ and $p_{\text {high }}, p_{\text {split }}$ (see Figure 3.3).

Furthermore, an increased performance reserve $\left(p_{\text {low }}\right)$ can also be useful when a higher acceleration demand is detected.

- The basic control strategy results in what is commonly referred to as a 'bang-bang' control [98]. A smoother transition between different reference speed levels is introduced within the interval $\pm x_{p, S o C}$ around the SoC pressure limits (see Figure 3.3).

- In the open circuit configuration of the SHHV transmission, there may be a risk of draining the system faster than the ICE and pump can recharge, particularly if needing to start up. A control parameter, $q_{r e f}$, is introduced and compared to the deviation in supply and load flow. If 


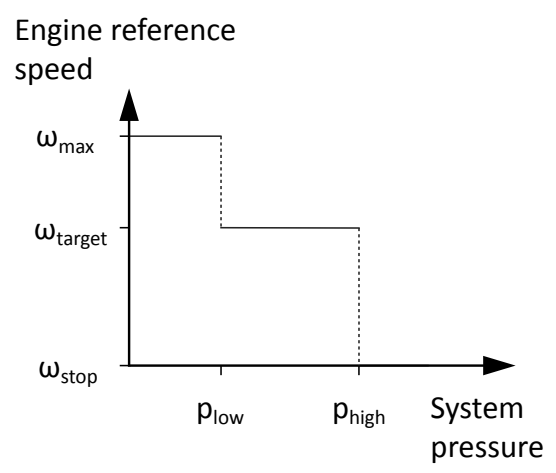

Basic SoC-based control

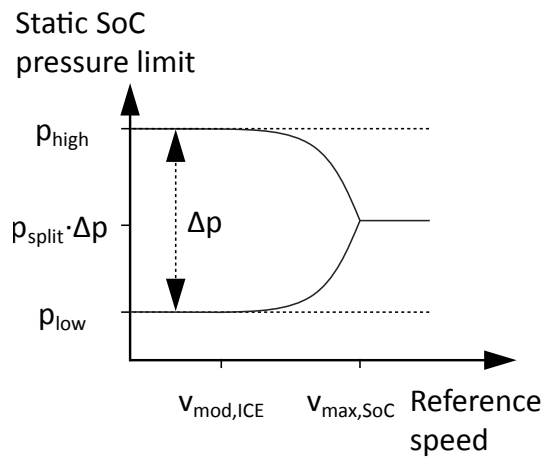

Dynamic reference speed-based SoC limit modulation

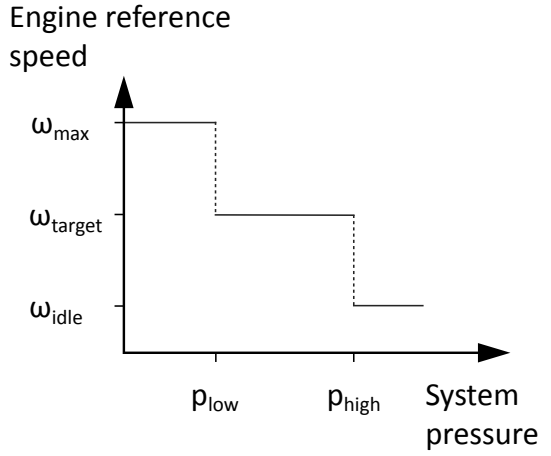

SoC-based control with idling for $v_{\text {ref }}>v_{\text {mod,ICE }}$

Engine reference

speed

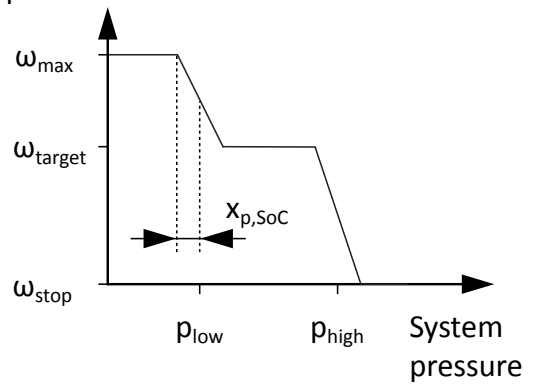

SoC-based control with transitions

Figure 3.3 Basic SoC-based control strategy and some of the modulations introduced. For better interpretation the $\mathrm{SoC}$ limits are represented as pressure levels.

the discrepancy becomes too large, the maximum allowed pump/motor displacement setting is reduced.

- Finally, during transition between different target operating speeds points, the pump load can undesirably slow down engine acceleration. This can be addressed by lowering pump displacement accordingly when required. 


\section{4 \\ Framework for Simulation-Based Optimization}

$\mathrm{T}$

HE SIMULATION MODEL is embedded in a Hopsan-based optimization framework to simultaneously size the system's main components and tune control parameters. In relation to a typical design process, as shown for example in [53], this integrates elements of both early and later design stages. It is, however, to be pointed out that the overall aim of the framework is not to obtain a final design, but to explore design options. The framework will be demonstrated and analysed for a limited-extent design problem.

Figure 4.1 [IV] illustrates the procedure employed in the SBO framework. Explicit Design Relations [99, 3] capture the effects the variation of design parameters during optimization has on system properties. They are largely captured in the scaling relationships described in Chapter 3.

Not only the simulation model, but also the entire optimization framework can be set up in the Hopsan environment. While SBO is expected to be a computationally demanding process, the fact that the software is freely available allows for it to be used on numerous computers in parallel, for example in a Linux cluster configuration [100]. 


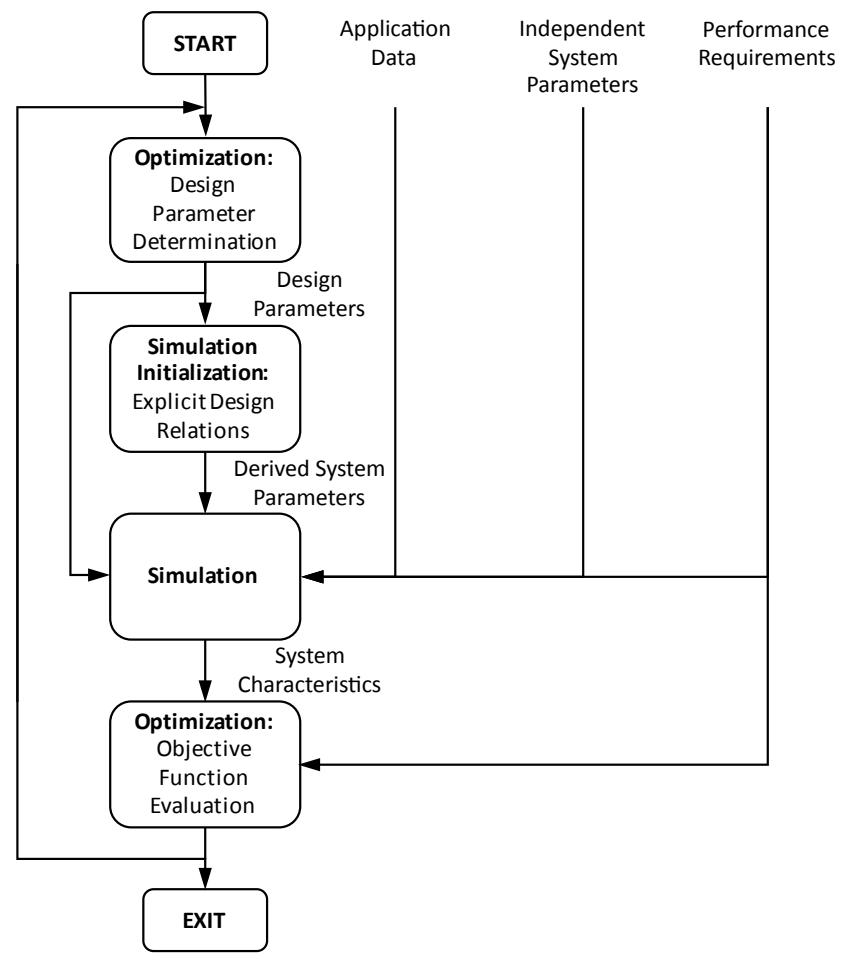

Figure 4.1 Simulation-based design framework [IV], based on [3]

\subsection{Optimization Problem Formulation}

\subsubsection{Optimization Objective Function}

The design of an SHHV transmission aims to fulfil a number of complex, and not necessarily concurring design objectives imposed by various stakeholders. Some of the quantifiable measures include fuel economy, greenhouse gas emissions, system costs and packaging considerations, as well as performance criteria. A vehicle's operating limits are typically expressed as acceleration performance, climbing ability (gradeability) and the maximum obtainable speed. Consequently, the design problem poses a multi-objective optimization problem (see e.g. $[101,102])$.

For the purposes of the SBO study, the focus of the optimization will be on the fuel consumption of the transmission. This is typically evaluated over a predefined mission in the most general sense, commonly a given velocity profile, a so-called drive cycle, for the vehicle to follow. Official testing procedures also 
include numerous boundary conditions for determining the fuel economy, which will be disregarded here. Due to the forward-facing nature of the simulation model, however, it needs to be guaranteed that the vehicle actually performs the driving task sufficiently [70]. Absolute deviation limits as employed in [28] (somewhat modulated in [50]) can be systematically abused; to prevent this, the total deviation of the vehicle speed $v_{v e h}$ from the reference drive cycle $v_{r e f}$ is related to the total distance covered, $x_{c y c l e}$, in the dimensionless Average Relative Velocity Deviation (ARVD) measure to quantify the tracking.

$$
A R V D=\frac{\int_{t=0}^{t_{\text {cycle }}}\left|v_{\text {ref }}(t)-v_{v e h}(t)\right| d t}{x_{\text {cycle }}}
$$

where $t_{\text {cycle }}$ describes the total duration of the drive cycle.

The transmission's fuel consumption over such a drive cycle needs to include, beyond what is derived from the operating points on the BSFC-map, an estimate of the additional fuel required for ICE start-ups [103], as well as a correction for the difference in accumulator $\mathrm{SoC}$ at the beginning and end of a driving mission.

Assessing the driveability of a vehicle transmission determines whether its power suffices for the driver demand. Such driving performance considerations had initially been addressed by various drive cycles, including high acceleration velocity profiles and highway velocities, individually and in combination. Later on, additional moderate maximum driving speed and acceleration requirements were evaluated simulation-based. Various combinations of drive cycles and performance limits form test cases for the design optimization.

To combine the various objectives [101], instead of weighing these targets against one another, the additional objectives to the fuel consumption are reformulated as constraints, and penalized if violated by a design. Furthermore, non-permissible system operation, e.g. where the system pressure drops too low, or a hydraulic machine's rotational speed exceeds its limit, is penalized.

\subsubsection{Design Parameters}

The principal design parameters to be addressed by the optimization procedure include the main components of the hydraulic hybrid transmission and the ICE and the static SoC pressure limits (cf. also Figure 3.2). More parameters have been added, especially for refining the control strategy where parameters were initially set based on engineering intuition. For the optimization implementation, all parameters are considered to be continuously variable, and for the optimization normalized relative to the corresponding parameter range. For the parameterization, an additional penalty is introduced to ensure $p_{\text {low }}<p_{\text {high }}$. 


\subsubsection{Optimization Problem}

The design optimization problem is formulated as follows:

$$
\min f(\mathbf{x})=F C(\mathbf{x})+\sum_{l=1}^{s} P_{l}(\mathbf{x})
$$

subject to

$x_{i, \min } \leq x_{i} \leq x_{i, \max } \quad, i=1 \ldots n$

with

$$
\begin{aligned}
& P_{l}(\mathbf{x})=\left\{\begin{array}{lll}
c_{P, l}+g_{l}(\mathbf{x}) & \text { if constraint } l \text { violated } \\
0 & \text { otherwise }
\end{array} \quad, l \in\{1, \ldots, r\}\right. \\
& P_{l}(\mathbf{x})=\left\{\begin{array}{ll}
c_{P, l} & \text { if constraint } l \text { violated } \\
0 & \text { otherwise }
\end{array}, l \in\{r+1, \ldots, s\}\right.
\end{aligned}
$$

where $\mathbf{x}$ is the vector containing all design parameters $x_{i},\left[x_{i, \min }, x_{i, \max }\right]$ represents the parameter limit for $x_{i}$, and $F C(\mathbf{x})$ is the fuel consumption of a particular design $\mathbf{x}$ after completion of a particular driving mission.

\subsection{Optimization Algorithm}

The optimization is conducted using the Complex-RF algorithm, which falls in the category of gradient-free direct search methods. The Complex algorithm was originally presented by Box [104], and maintains a so-called complex of search points, the worst of which is to be replaced by its reflection through the remainder of potential designs. Modifications (e.g. [105]) address the reflection behaviour; in the Complex-RF variant [106], a random element and a forgetting factor favouring recently obtained solutions are included. Variants of the Complex algorithm have been successfully used for the optimization of for example hydrostatic transmission control [82], aircraft systems [106], industrial robots [107], and the design of hydro-mechanical transmissions [93].

The optimization algorithm is expected to provide a good compromise between computational load and quality of results. Population-based methods are generally considered reliable for identifying globally optimal solutions (also observed for example in [108]), but take a long time to converge; for this reason, Sun [60] combined a genetic algorithm with simulated annealing. Matheson and Stecki [109] reported difficulties in getting the gradient-based FMINCON method to successfully complete the optimization, and Fellini [110] pointed out that the Complex method had proven successful in the optimization problem provided, and handled problems with discontinuities and noise well. Filipi et al. [28] utilized the sequential quadratic programming algorithm in combination with a multi-start approach, distributing starting points for several separate optimization attempts. 
The Complex-RF algorithm uses randomly distributed starting points for the initial complex of search points as well. Furthermore, similar to the approach in [28] optimization experiments are repeated multiple times to account for stochastic elements introduced by both the starting points and the randomization factor. Unlike the parallel job method presented in [111], however, each experiment is allowed to finish independently.

The Complex-RF algorithms operates in a purely sequential fashion. In order to use the parallel capabilities of computers, Braun and Krus [111] suggested a number of modified approaches summarized as Complex-RFP algorithm, which are briefly described in paper $[\mathrm{V}]$. These algorithms are also tested and compared to both the Complex-RF as well as a naturally parallelized populationbased Particle Swarm Optimization (PSO) method (cf. [111], although here on a more complex optimization problem). Derivative-free optimization approaches which aim to develop a representation of the objective function for evaluation (see examples in $[112,113])$ are not considered.

\subsection{Optimization Performance Evaluation}

In order to evaluate the performance of an optimization method, how well the algorithm can find the optimal solution at what computational cost needs to be captured (cf. [114], for which a number of approaches are listed for example in $[115,116])$. Here, the Entropy-Rate-Based Performance Index (ERI) [115] is used, which is based on Shannon's [117] information theory. The design process is interpreted as an information-gathering process within the design space with the aim of reducing the inherent uncertainty in $n$ design parameter values $x_{i}$ within the parameter range $x_{i, R}=x_{i, \max }-x_{i, \min }$ to defined limits:

$$
\delta_{x, i}=\frac{\Delta x_{i}}{x_{i, R}} \leq \varepsilon_{x} \quad \forall i
$$

where $\Delta x_{i}$ denotes the spread of parameter $i$, i.e. its absolute uncertainty, $\delta_{x, i}$ is consequently its relative uncertainty, and $\varepsilon_{x}$ the convergence criterion for all parameters.

The information gathered is the information entropy $H_{x}$. The derivation of its formula [115] is documented in paper [V]. The performance index $\Phi$ then relates the information entropy $H_{x}$ to an optimization effort measure $N_{m}$.

$$
\Phi^{(1)}=\frac{H_{x}^{(1)}}{N_{m}}=\frac{-\sum_{i=1}^{n} \log _{2} \delta_{x, i}}{N_{m}}=\frac{-n \log _{2} \varepsilon_{x}}{N_{m}}
$$

$N_{m}$ can for example be the number of optimization iterations required to reach the convergence criterion, or, in order to capture the total computational load of parallelly operating optimization methods, the total number of objective function evaluations (denoted as $\Phi_{\mathrm{IT}}$ and $\Phi_{\mathrm{FE}}$, respectively). 
The basic performance index definition can furthermore be modified $\left(\Phi^{(2)}\right)$ to include the probability of an optimization algorithm finding the optimal solution, the success rate $P_{\text {opt }}[115]$.

$$
\begin{aligned}
\Phi^{(2)} & =\frac{H_{x}^{(2)}}{N_{m}}=\frac{\sum_{i=1}^{n} H_{x, i}^{(2)}}{N_{m}} \\
& =\frac{1}{N_{m}}\left(\left(1-P_{o p t}\right) \log _{2}\left(\frac{1-P_{o p t}}{1-\prod_{i=1}^{n} \delta_{x, i}}\right)+P_{o p t} \log _{2}\left(\frac{P_{o p t}}{\prod_{i=1}^{n} \delta_{x, i}}\right)\right) \\
& =\frac{1}{N_{m}}\left(\left(1-P_{o p t}\right) \log _{2}\left(\frac{1-P_{o p t}}{1-\varepsilon_{x}^{n}}\right)+P_{o p t} \log _{2}\left(\frac{P_{o p t}}{\varepsilon_{x}^{n}}\right)\right)
\end{aligned}
$$




\section{5 \\ Optimization Experiments}

T

HE SBO FRAMEWORK developed has been tested in a number of optimization experiments for a particular vehicle application. This chapter will provide an overview of the experiments conducted and the motivation behind them. Selected results are included that illustrate the framework in use.

\subsection{Vehicle Application}

As case study, a vehicle of the light-duty category has been chosen (see Table 5.1 for basic vehicle data). The focus away from a passenger vehicle may allow for more moderate performance requirements, especially when predominantly considering urban and suburban driving conditions. The vehicle is considered with half of the maximum load (calculated from the kerb weight of the baseline vehicle) when evaluated over a deterministic drive cycle as an added driveability requirement. Assuming the kerb weight to include a conventional transmission, engine down-sizing considerations are based on the specification of baseline diesel engine assumed for this vehicle. It should, however, be noted that transmission components' weights are not compensated for. Performance limits for the optimization problem (eq. 4.2) are given in Table 5.2. While fuel consumption and $A R V D$ are evaluated for the half-loaded vehicle, the other performance requirements are simulated under optimal conditions, i.e. without load and with a fully charged accumulator.

In the design studies, a number of standard drive cycles (Figure 5.1, see [118] for an overview) are used to evaluate driveability and fuel economy. These drive cycles differ in duration and driving characteristics (see Table 5.3 for a summary of data). The EPA's Urban Dynamometer Driving Schedule (UDDS) is a ty- 
Table 5.1 Basic vehicle data

\begin{tabular}{lc}
\hline Kerb weight & $1800 \mathrm{~kg}$ \\
Gross weight & $3500 \mathrm{~kg}$ \\
Load considered $\quad$ (for drive cycles) & $850 \mathrm{~kg}$ \\
\hline Effective front area & $1.3 \mathrm{~m}^{2}$ \\
Wheel radius/final drive gear ratio & $0.1 \mathrm{~m}$ \\
\hline Rolling resistance coefficient & $0.02[-]$ \\
\hline Default diesel engine & \\
$\quad$ Maximum torque & $367 \mathrm{Nm}$ \\
Maximum power & $130 \mathrm{~kW}$ \\
\hline
\end{tabular}

Table 5.2 Vehicle performance requirements

\begin{tabular}{lcc}
\hline Performance requirement & Limit & $\begin{array}{c}\text { Relevant } \\
\text { papers }\end{array}$ \\
\hline$A R V D$ & $\leq 1.0 \%$ & {$[\mathrm{II}]-[\mathrm{V}]$} \\
Maximum cruise speed & $130 \mathrm{~km} / \mathrm{h}$ & {$[\mathrm{IV}, \mathrm{V}]$} \\
Acceleration $(0$ to $100 \mathrm{~km} / \mathrm{h})$ & $\leq 15 \mathrm{~s}$ & {$[\mathrm{IV}, \mathrm{V}]$} \\
\hline
\end{tabular}

pical test cycle representing suburban driving, while the New York City Cycle (NYCC) captures aggressive inner-city accelerations. US-American highway speeds are represented in the Highway Fuel Economy Test (HWFET), whereas New European Driving Cycle (NEDC) and Worldwide harmonized Light vehicles Test Cycle, class 3 (WLTC3) reach European speed limits as well. 

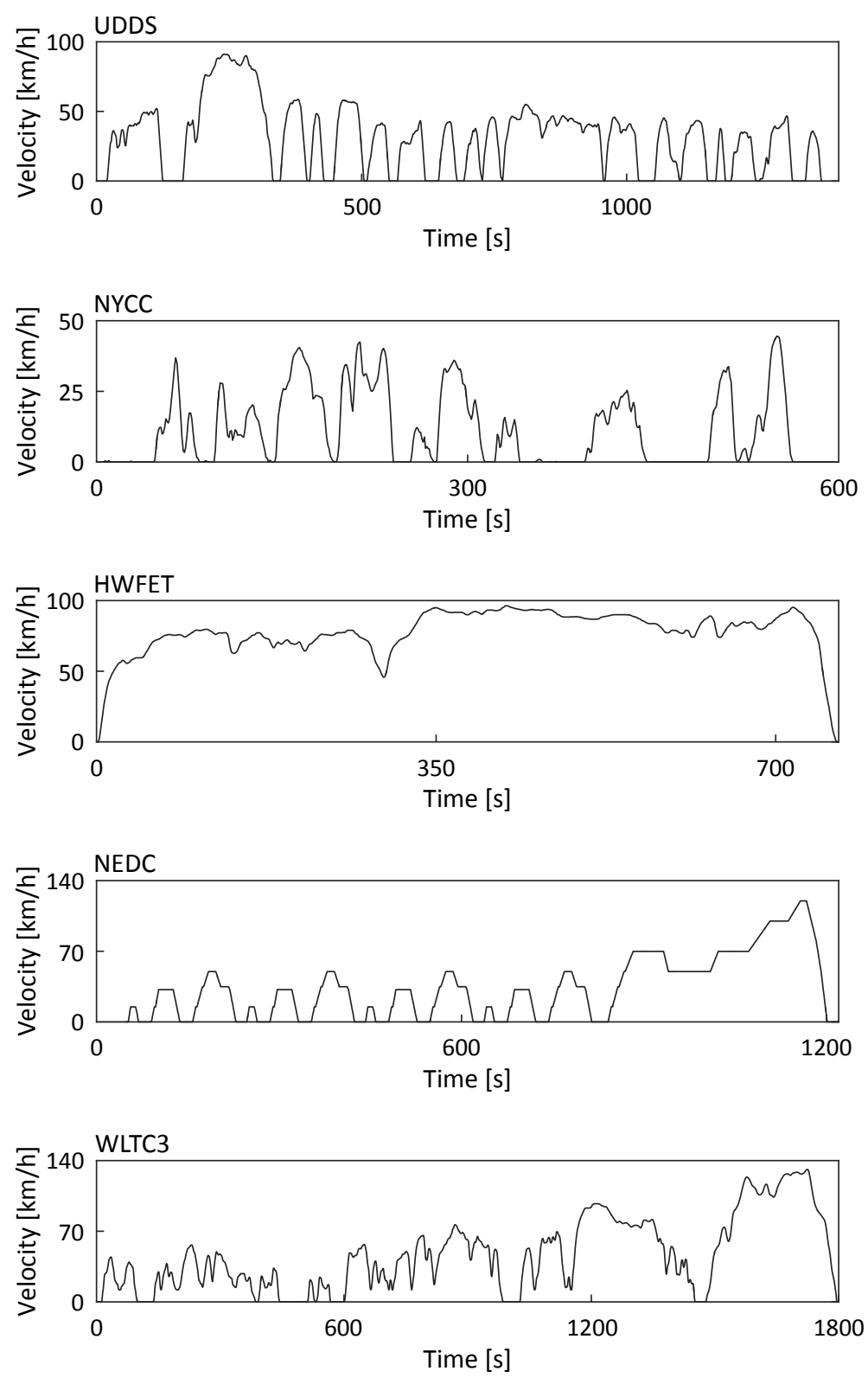

Figure 5.1 Velocity profiles for standard drive cycles 
Table 5.3 Drive cycles used for SHHV design (data from [118], WLTC3 data from velocity profile (version 5))

\begin{tabular}{lcccc}
\hline $\begin{array}{c}\text { Drive } \\
\text { cycle }\end{array}$ & Duration & Distance & $\begin{array}{c}\text { Maximum } \\
\text { speed } \\
{[\mathbf{k m} / \mathbf{h}]}\end{array}$ & $\begin{array}{c}\text { Average } \\
\text { speed } \\
{[\mathbf{k m} / \mathbf{h}]}\end{array}$ \\
\hline UDDS & 1369 & 12.0 & 91.2 & 31.6 \\
NYCC & 598 & 1.9 & 44.5 & 11.5 \\
HWFET & 765 & 16.5 & 96.3 & 77.7 \\
NEDC & 1180 & 11.0 & 120.1 & 33.6 \\
WLTC3 & 1800 & 23.3 & 131.3 & 46.5 \\
\hline
\end{tabular}

\subsection{Experiment Overview}

In the appended papers, a number of experiments were conducted for SHHV design and analysis (see Table 5.4 for an overview). Initial parameter sweeps aimed to find suitable designs for individual drive cycles (UDDS, NYCC; paper $[\mathrm{I}]$ ), with a focus on successfully fulfilling the implicit driving requirements. In the first optimization studies [II, III], drive cycles were studied individually and in combination for more varied performance demands. Focus was thereby on the principal design parameters (main components and SoC pressure limits). Subsequently, sensitivity studies were conducted to analyse the robustness of the results obtained to various parameter and condition variations. These included the design parameters themselves, a wide range of system parameters, as well as the driving profiles. In the following optimization experiments [IV], component constraints were refined and the additional acceleration and maximum driving speed requirements were included to obtain increased driveability robustness. Based on these results [V], focus shifted further towards variations in the optimization problem formulations, not only in the objective function but also including design parameters considered and the optimization algorithms applied.

In this section, selected optimization results obtained for papers [IV] and [V] are presented. It should be noted that the results from paper [IV] have been updated to match the baseline experiment and its results in paper [V].

\subsubsection{Baseline Optimization Experiments}

The variations on the optimization experiments which follow are compared to a basic optimization task for reference. For continuity reasons, this was chosen to be an optimization over the UDDS, including additional performance requirements and component operation limits. The optimization problem contains nine design parameters (see Table 5.5). In comparison to the principal para- 
Table 5.4 Experiments conducted in the appended papers

\begin{tabular}{lll}
\hline Paper & \multicolumn{1}{c}{ (Optimization) experiments } & $\begin{array}{c}\text { Analysis of optimization } \\
\text { results }\end{array}$ \\
\hline I & $\begin{array}{l}\text { Parameter sweeps for } \\
\text { UDDS, NYCC (individually) }\end{array}$ \\
II & $\begin{array}{l}\text { Optimization over UDDS, NYCC } \\
\text { (individually and in combination, }\end{array}$ \\
& 7 parameters) & \\
& Optimization over UDDS, NYCC & Sensitivity analyses: \\
III & and HWFET & design parameters, \\
& (individually and in combination, & system parameters, \\
& drive cycle variations \\
& Optimization over UDDS, NEDC & Robustness test over non- \\
IV & optimized drive cycles \\
& (individually, 9 parameters, with & \\
& and without driving requirements) & \\
Optimization over UDDS & Sensitivity analysis in \\
V & (9, 13 and 16 parameters) & (9) design parameters \\
& &
\end{tabular}

meters (see Chapter 4.1.2), this also includes the engine flywheel inertia $J_{F W}$ as well as parameters for the SoC pressure modulation $\left(p_{\text {split }}\right)$ and for limiting the pump/motor displacement setting if necessary $\left(p_{\text {split }}\right)$. To solve the design problem, the sequential Complex-RF algorithm is used with parameters (see Table 5.6) matching closely those obtained through meta-optimization by Krus and Ölvander [115].

The results displayed in Figure 5.2 show fairly little variation in the principle design parameters, especially hydraulic pump/motor and combustion engine. The lower static SoC pressure, $p_{l o w}$, converges towards the parameter range limits, presumably due to the dynamic modifications providing a sufficient performance reserve. The parameter is not excluded from the following experiments to maintain comparability in optimization performance. The nonprincipal parameters show the greatest spread, indicating an increased robustness of the model towards their variation.

Figure 5.3 illustrates the system operation of an optimized design during the first 400 seconds of the UDDS. This part of the drive cycle includes its maximum velocity driving event. In the acceleration around $200 \mathrm{~s}$, the deviation between reference and actual vehicle speed becomes visible, and leads to a dynamic adjustment of $p_{\text {low }}\left(\mathrm{SoC}_{\text {low }}\right)$ and maximum power from the engine. While the engine power does not suffice to immediately catch up with the reference signal, the $A R V D$ performance measure is only moderately affected. During the high-speed driving event the modulated upper state-of-charge limit can also be observed, as well as the prevented engine shutdown due to the current vehicle 
Table 5.5 Design parameters for baseline optimization problem

\begin{tabular}{|c|c|c|c|c|}
\hline Parameter & Symbol & Unit & $\begin{array}{l}\text { Lower } \\
\text { Limit }\end{array}$ & $\begin{array}{l}\text { Upper } \\
\text { Limit }\end{array}$ \\
\hline Pump displacement & $D_{p}$ & $\mathrm{~cm}^{3} / \mathrm{rev}$ & 25 & 250 \\
\hline Pump/motor displacement & $D_{p m}$ & $\mathrm{~cm}^{3} / \mathrm{rev}$ & 25 & 250 \\
\hline Engine flywheel inertia & $J_{F W}$ & $\mathrm{~kg} \mathrm{~m} \mathrm{~m}^{2}$ & 0.001 & 1 \\
\hline $\begin{array}{l}\text { Upper static state-of-charge } \\
\text { pressure }\end{array}$ & $p_{\text {high }}$ & $\mathrm{MPa}$ & 15.0 & 45.0 \\
\hline $\begin{array}{l}\text { Lower static state-of-charge } \\
\text { pressure }\end{array}$ & $p_{\text {low }}$ & $\mathrm{MPa}$ & 12.5 & $44.0^{\mathrm{a}}$ \\
\hline $\begin{array}{l}\text { High-speed target pressure } \\
\text { (relative between } p_{\text {high }} \\
\left.\text { and } p_{\text {low }}\right)\end{array}$ & $p_{\text {split }}$ & - & 0.0 & 1.0 \\
\hline $\begin{array}{l}\text { Reference flow parameter for } \\
\text { pump/motor displacement } \\
\text { setting reduction }\end{array}$ & $q_{r e f}$ & $\mathrm{~m}^{3} / \mathrm{s}$ & 0.001 & 0.05 \\
\hline Maximum engine torque & $T_{\max }$ & $\mathrm{Nm}$ & 75 & 400 \\
\hline Accumulator volume & $V_{0, a c c}$ & $10^{-3} \mathrm{~m}^{3}$ & 10 & 100 \\
\hline
\end{tabular}

${ }^{\mathrm{a}}$ An additional condition ensures a minimum (static) state-of-charge pressure difference of $\left(p_{\text {high }}-p_{\text {low }}\right) \geq 5 \cdot 10^{6} \mathrm{~Pa}$.

Table 5.6 Parameters for Complex- $R F$ algorithm for an $n$-dimensional problem

\begin{tabular}{lc}
\hline Parameter Name & Parameter Value \\
\hline Maximum number of iterations $N_{\text {m,max }, \text { IT }}$ & 4000 \\
Number of search points & $2 n$ \\
Reflection factor $\alpha$ & 1.3 \\
Randomization factor $\beta$ & 0.3 \\
Forgetting factor $\gamma$ & 0.3 \\
\hline
\end{tabular}




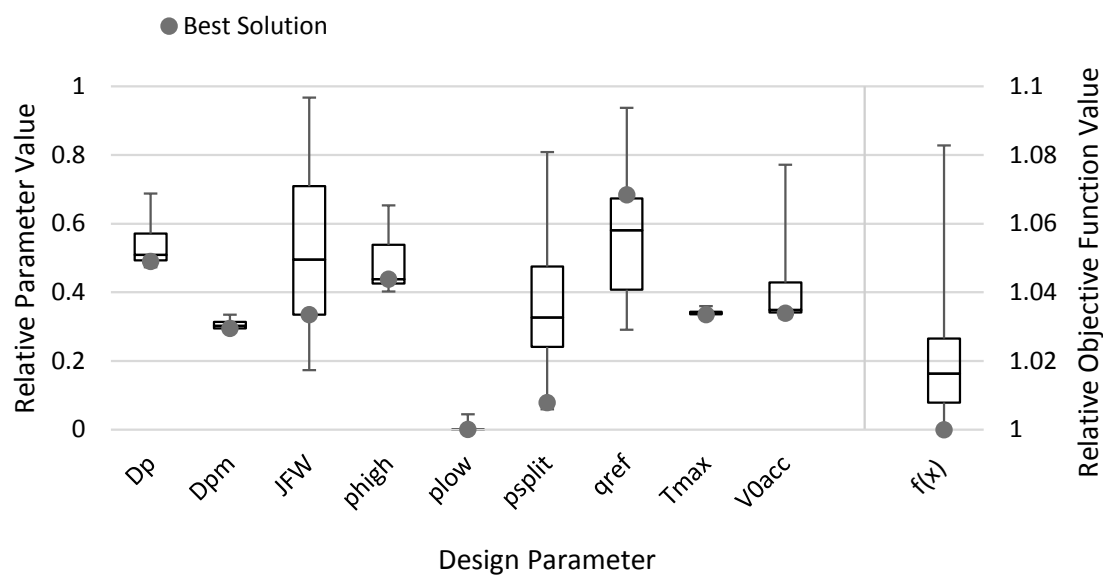

Figure 5.2 Spread of design parameters in resulting designs and objective function value from baseline optimization (25 independent optimizations, $U D D S)$. All runs finished due to convergence in parameter values. [V]

velocity $\left(>v_{m o d, I C E}\right)$.

The hybridization of a transmission aims to recuperate as much as possible of the kinetic energy during braking into the energy storage device. In Figure 5.4 it can be seen how the accumulator captures the energy from moderate vehicle speeds minus losses during the braking phase, keeping the total energy in the system close to constant (e.g. between 100 and $200 \mathrm{~s}$ in Figure 5.4). The kinetic energy from the maximum velocity, however, cannot be recuperated: the design optimization lead to a smaller accumulator than necessary for that, based on the drive cycle characteristics (see Figure 5.1 and Table 5.3 as well as the discussion in Chapter 2.3). The kinetic energy in the engine flywheel is negligible.

\subsubsection{Variation: Drive Cycles for Optimization}

While the performance requirements included in the objective function can ensure driveability under certain conditions and within specified limits, the optimized design will nonetheless depend heavily on the drive cycle used to evaluate fuel consumption and $A R V D$. Three different drive cycles are studied: UDDS, NEDC and WLTC3 (Figure 5.5). Again, the non-principal design parameters are characterized by wide spreads and far outliers. Pump/motor size and lower static SoC pressure limit show little variation, indicating that the hydraulic component's sizing may be dominated by the drive-cycle-independent performance requirements. For each drive cycle, the ICE is again similarly si- 

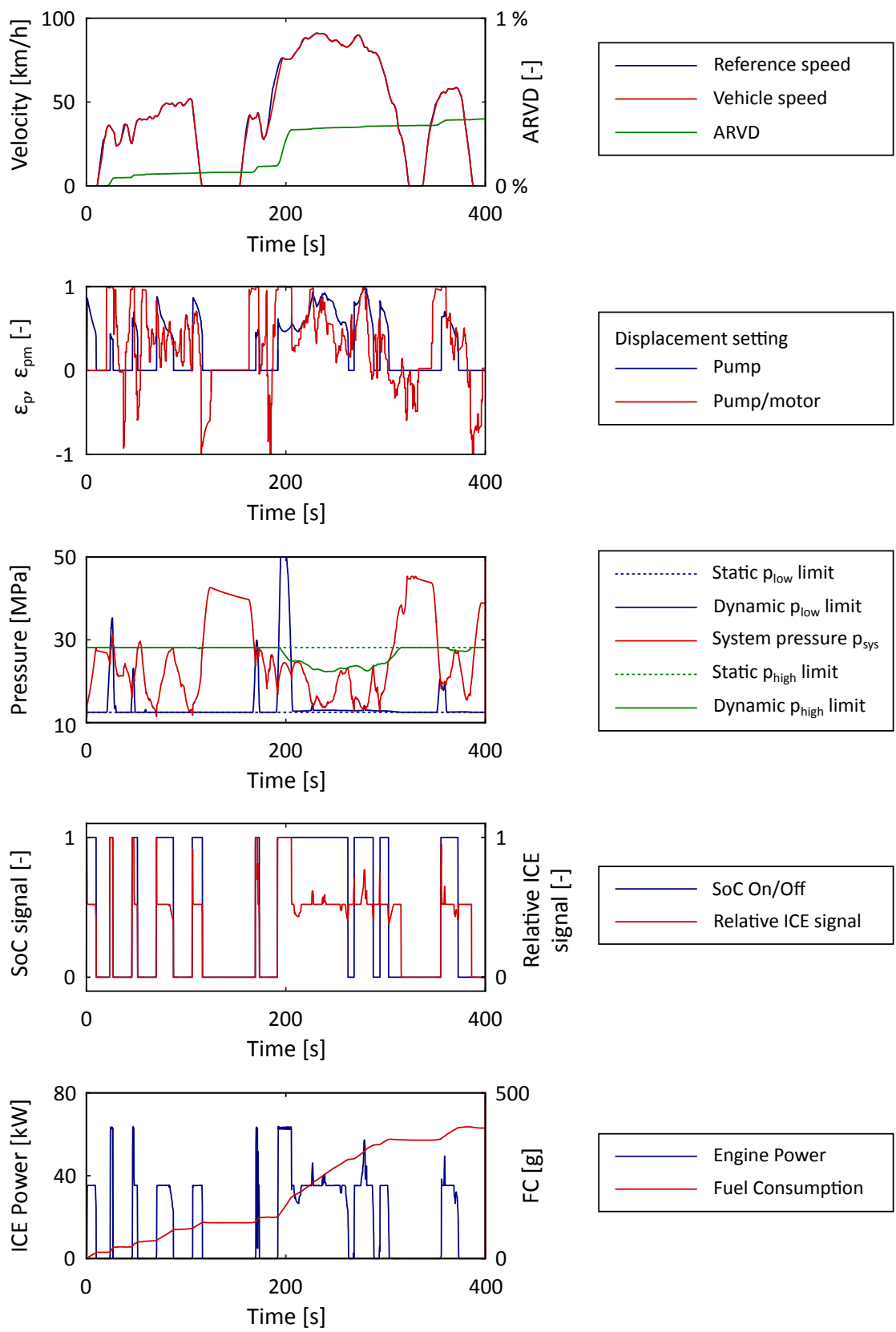

Figure 5.3 System operation during the first $400 \mathrm{~s}$ of the UDDS (best design obtained from baseline optimizations) 


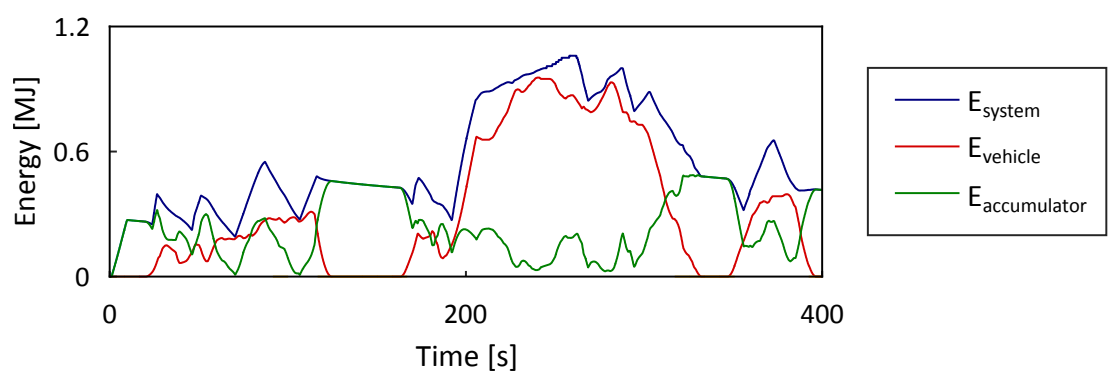

Figure 5.4 Energy in SHHV system during the first $400 \mathrm{~s}$ of the UDDS (best design obtained from baseline optimizations) including vehicle and flywheel kinetic energy and accumulator energy content

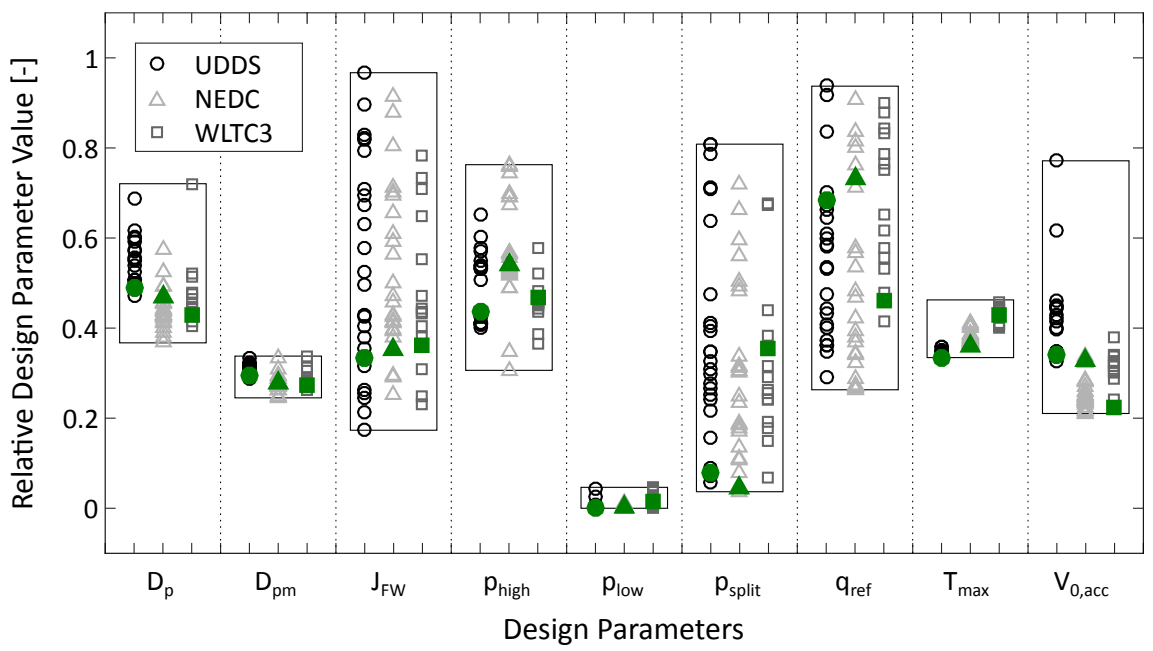

Figure 5.5 Spread in relative design parameter values from design optimization for different drive cycles. Green, enlarged markers indicate values for the best obtained solution, respectively.

zed, but between the different solution groups there are differences. A similar, less pronounced, effect can be observed for the hydraulic accumulator, especially in NEDC. In the UDDS, comparably larger accumulators indicate this test case benefiting more from the possibility for energy recuperation. 
Table 5.7 Design parameters for optimization problem of increased problem dimensionality

\begin{tabular}{lccccc}
\hline Parameter & Symbol & Unit & $\begin{array}{c}\text { Lower } \\
\text { Limit }\end{array}$ & $\begin{array}{c}\text { Upper } \\
\text { Limit }\end{array}$ & $\begin{array}{c}\text { Default } \\
\text { Value }\end{array}$ \\
\hline $\mathrm{CP} 1$ & $v_{\max , \mathrm{SoC}}$ & $\mathrm{km} / \mathrm{h}$ & 100 & 150 & 130 \\
$\mathrm{CP} 2$ & $v_{\bmod , \mathrm{ICE}}$ & $\mathrm{km} / \mathrm{h}$ & 30 & 80 & 50 \\
$\mathrm{CP} 3$ & $D B_{\Delta v}$ & - & 0 & 3 & 0.1 \\
$\mathrm{CP} 4$ & $K_{\Delta v}$ & $1 /(\mathrm{m} / \mathrm{s})$ & 0 & 3 & 0.6 \\
\hline
\end{tabular}

\subsubsection{Variation: Problem Dimensionality for Optimization}

The baseline experiment addresses three additional design parameters beyond the stated principal design parameters. The simulation model, however, contains numerous parameters that are set without comprehensive analysis. Their inclusion in the optimization problem may lead to improved solutions compared to the baseline case but may at the same time require more optimization iterations to converge.

To illustrate the effects of an increased design space by means of increased problem dimensionality, four additional design parameters, CP1 - CP4 (see Table 5.7), are added to the baseline parameter set in paper [V]. $v_{\text {mod,ICE }}$ (CP2) describes the vehicle reference speed from which on ICE shutdown is prevented in favour of idling. The other parameters concern the SoC pressure modulation: $v_{\max , \mathrm{SoC}}(\mathrm{CP} 1)$ is the limit for the speed-dependent adjustment, whereas CP3 and CP4 adjust the impact of the instantaneous acceleration demand on the dynamic lower SoC limit. The maximum number of iterations, $N_{m, \max , \mathrm{IT}}$, is increased to 7000 to ensure convergence.

Including more control parameters in the SHHV design optimization yields an objective function value improved by approximately $6 \%$ (Figure 5.6). The added parameters modulate the control strategy and thus the accumulator charge profile. Most affected is the upper static SoC pressure limit which shows a wider spread, and consequently the hydraulic pump, which needs to be capable of delivering said charge. With the modulation, a larger accumulator maintains an energy recuperation reserve. The added control parameters, with the exception of CP3's interquartile range, show large spreads; the best design's parameters appear to deviate considerably from the ones previously set.

A further extension of the design space, including the SoC transition interval, a pump displacement setting modulation during ICE acceleration, and the engine target speed under normal charging, did not yield further improvement in fuel economy (see paper $[\mathrm{V}]$ ). 


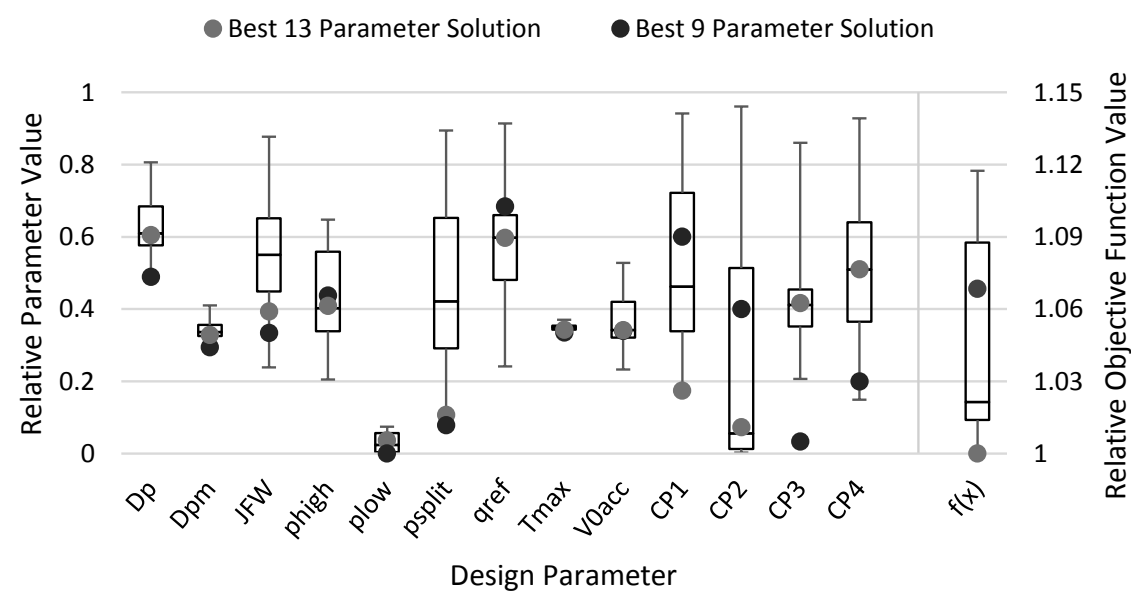

Figure 5.6 Spread in relative design parameter and objective function values from 25 optimizations with 13 design parameters. All runs finished due to convergence in parameter values. For comparison, the best design obtained with 9 parameters is included. Note that $\mathrm{CP} 1-\mathrm{CP} 4$ were constant during the 9 parameter optimization. [V] 


\subsubsection{Variation: Optimization Algorithms for Series Hydraulic Hybrid Design}

Previously, Braun and Krus [111] had introduced parallel implementations for the Complex-RF algorithm, and tested these over mathematical test functions and a small-scale simulation model. The tests are repeated with the SHHV model, including one implementation of the PSO for comparison, with the optimization parameters matching those from [111] (Table 5.8), with the exception of the slightly higher forgetting factor, which was shown to have limited impact (see paper $[\mathrm{V}]$ ). Appendix A.1 gives an overview over the computational hardware used for the different algorithms.

Due to the spread in solutions observed in the baseline scenario (see Figure 5.2), the performance index (eq. 4.4, 4.5) has been modified to circumvent an arbitrarily set success rate, and rather take into account all $m$ solutions (see [V] for the detailed motivation and derivation):

$$
\begin{aligned}
& \Phi^{(3)}=\frac{H_{x}^{(3)}}{N_{m}}=\frac{\sum_{j=1}^{m}\left(\frac{1}{m} \log _{2}\left(\frac{1 / m}{\prod_{i=1}^{n} \delta_{x, i, j}^{*}}\right)\right)}{N_{m}} \\
& \text { with } \\
& \delta_{x, i, j}^{*}= \begin{cases}2\left|x_{i, j}-x_{i, j^{*}}\right| / \Delta x_{i, R} & \text { if } j \neq j^{*} \\
\varepsilon_{x} & \text { if } j=j^{*} \text { or } 2\left|x_{i, j}-x_{i, j^{*}}\right| \leq \varepsilon_{x}\end{cases}
\end{aligned}
$$

The index $j$ thereby refers to one optimization, $j^{*}$ the optimization yielding the best solution.

To characterize the spread in the objective function values $f(\mathbf{x})$ of all solutions, an equivalent output-side entropy $H_{y}$ is defined $([\mathrm{V}])$ as

$$
H_{y}=\sum_{j=1}^{m} H_{y, j}=-\sum_{j=1}^{m} \log _{2}\left(\frac{f(\mathbf{x})_{j}}{f(\mathbf{x})_{j^{*}}}-1\right)
$$

Table 5.9 summarises the results for the baseline case, various ComplexRFP implementations with two or four parallel threads, as well as results for the PSO algorithm. $\Phi^{(3)}$ and $H_{y}$ are thereby calculated with respect to the global optimum obtained through the population-based optimization method.

The results show that while PSO leads to the most converged objective function values $\left(H_{y}\right)$, it is outperformed by the sequential and parallel Complex$\mathrm{RF}$ implementations, in particular due to the high number of function evaluations required (see also Figure 5.7).

The distinction between $\Phi_{\mathrm{IT}}^{(3)}$ and $\Phi_{\mathrm{FE}}^{(3)}$ illustrates the effect of parallelization, i.e. when a sufficient number of parallel threads are available for a parallelized optimization algorithm. It should be noted that if high-end computers with sufficient parallel capability are available, the PSO performance may be more acceptable. 


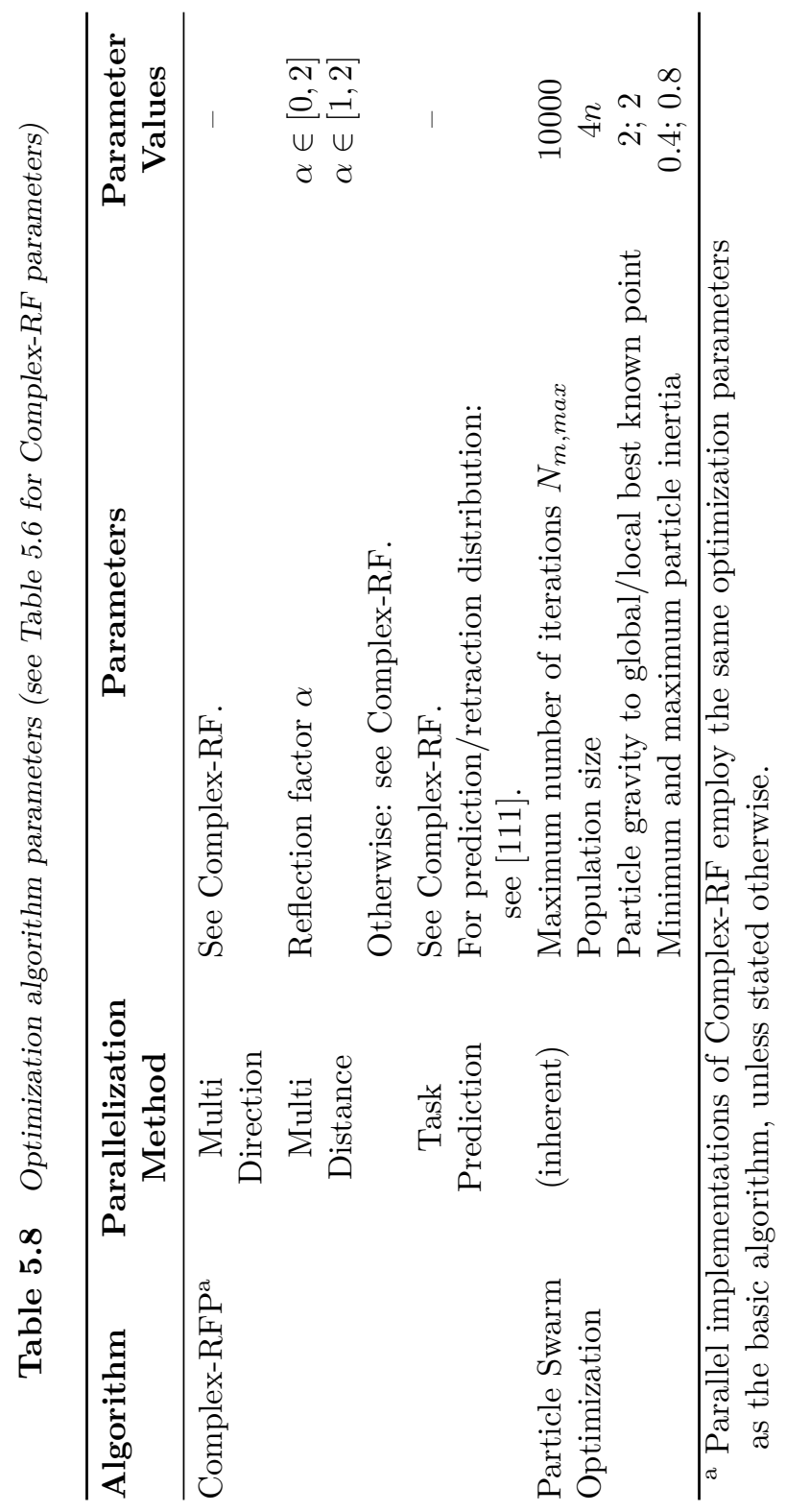




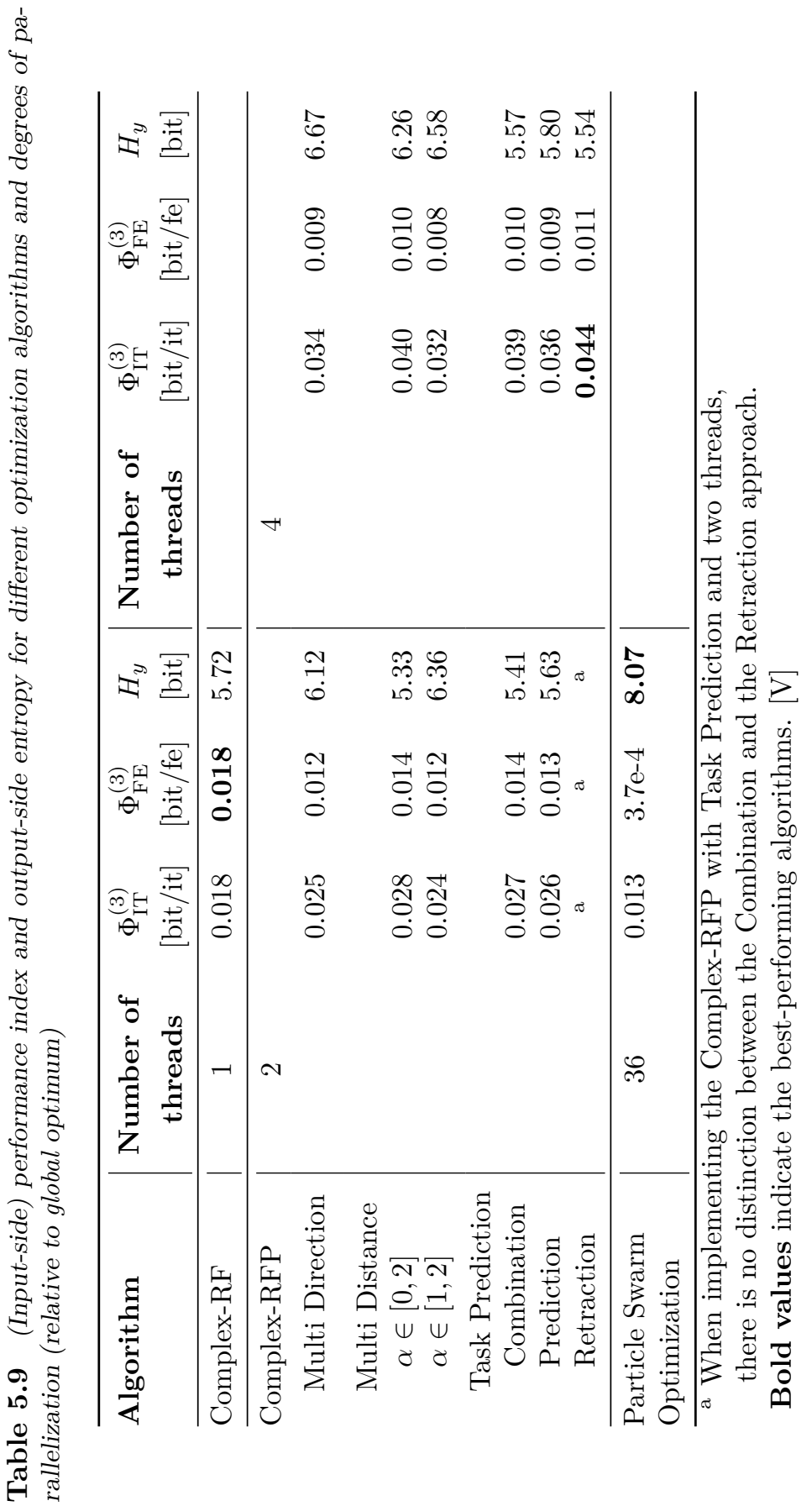




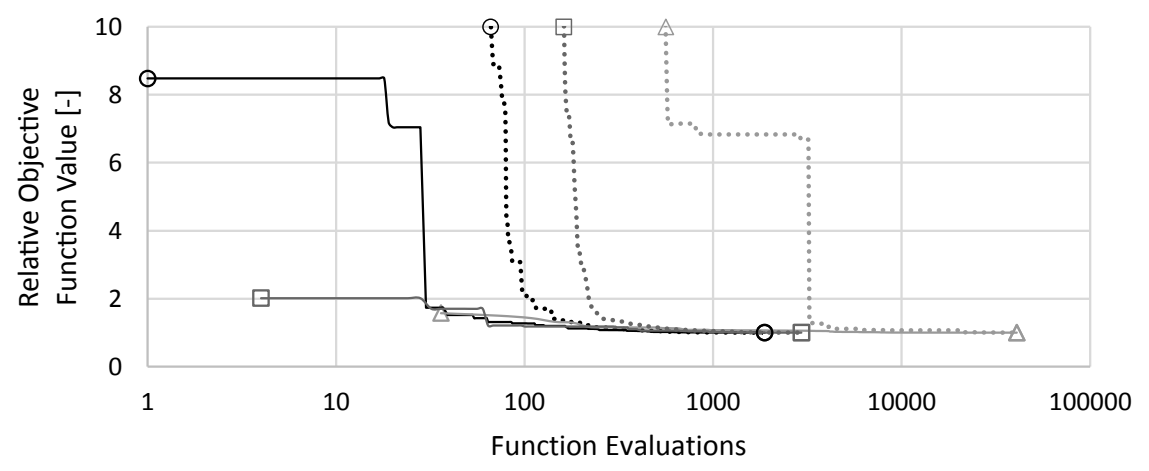

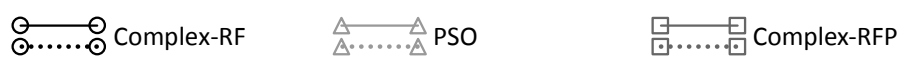

Figure 5.7 Best and worst objective function value over the number of function evaluations for each optimization algorithm's experiment yielding the respective best final solution (dotted lines indicate the worst value, start and end points are marked) 


\section{6}

Discussion

$\mathrm{T}$

HE DESIGN OF hydraulic hybrid transmissions is a complex endeavour. Additional degrees of freedom and numerous potential advantages offer opportunities for design decisions which need to be made while considering a multitude of interactions and consequences. Computational tools like simulation models and numerical optimization, even combined to simulation-based optimization (SBO), can be useful tools to support the design process.

Alternative transmission technologies, like hybrid instead of conventional drivelines, hydraulic hybrid instead of hybrid electric transmissions, or entirely new solutions gain traction by offering one or several advantages over the traditional candidates. Therefore, during the design decision process comparable system representations are needed, whether physical prototypes, or trustworthy, i.e. validated, models of the candidate systems in question. A validation of the complete simulation model has not been conducted for this thesis. For the main hydraulic components, however, the models are based on established knowledge and have furthermore been validated separately. The system model has been, through the optimization experiments, subjected to extensive tests aiding in identifying and rectifying major weaknesses.

For a fair comparison for a given application, each solution needs to be represented at their peak performance. For HHVs this includes topology selection, detailed configuration, selection of appropriate components and their sizing, and close (enough) to optimal control. Many of these aspects are typically decided based on engineering intuition. While a comprehensive comparison is costly, computational tools can at the very least provide valuable support, especially if they offer modular properties [119], e.g. to study different topologies and configurations. The optimization framework presented in this thesis aims to optimize both component sizes and control strategy. While a rule-based control approach does not guarantee globally optimal operation, it is directly implementable, and its use when simultaneously addressing components and control limits the complexity and computational load of the optimization pro- 
blem compared to e.g. dynamic programming approaches.

To give close to full information, an analysis needs to capture, quantify and normalize all relevant aspects of comparison. Fuel economy and driveability are typically in focus when it comes to transmissions, and the consequences of component scaling including limitations need to be captured. Fuel consumption, and partially driving performance, were evaluated based on standard drive cycles. While ensuring comparability of test results, their deterministic nature and lack of real-life aspects such as road grade limit the meaningfulness of the results. The drive cycles' representativeness for actual driving conditions is relevant to ensure robustness and prevent sub-optimality of vehicle designs [120]; while they are commonly used for design and evaluation, adaption to changing driving conditions is needed to maintain representativeness. The impact of using different drive cycles in the design process is illustrated in various optimization experiments. In papers [II] and [III], several drive cycles are studied in combination with respect to fuel consumption and driving performance as dictated by the velocity profile. Papers $[\mathrm{IV}]$ and $[\mathrm{V}]$ focus on performance aspects, evaluating fuel economy over single drive cycles, while establishing additional performance requirements.

Beyond the objectives mentioned so far, an evaluation can include greenhouse gas emissions (see e.g. [121, 122]), system and operating cost (see e.g. [35, 123]), packaging considerations (see e.g. [124]), and also qualitative aspects such as the driver experience (discussed for example in $[43,84]$ ). The framework presented here does not address these aspects, it can, however, be extended to include both simulated and statically evaluated additional constraints.

Even if all data for all of the aspects above is given, a simulation model capturing every detail becomes too heavy to manage. Between backward-facing quasi-static and forward-facing dynamic models of varying detail, the challenge is to establish the appropriate form to represent the information and knowledge available, and to develop, synthesize and ultimately evaluate it further. Either type can also fulfil supportive functions to the other, e.g. by providing benchmarks for control strategy evaluation or an implementation environment.

For SBO, next to a suitably accurate simulation model, the optimization procedure needs to be configured appropriately. This includes the optimization objective (see above), various aspects of design parameterization (selection of parameters, continuous, mixed or discrete definition, range, uncertainty, etc.) and an algorithm appropriate for the simulation model, optimization problem formulation, computational infrastructure and desired level of optimization accuracy and performance. A possibility to consider is that multi-level optimizations (see e.g. [28]) allow contrasting approaches to be combined or may help to improve optimization efficiency.

Once optimization results have been obtained, they open possibilities for further analysis and insight. Preliminary optimization studies can be useful in SBO to verify optimization results with respect to both simulation model and problem formulation, and can help to identify and explore trade-offs. Analysis 
of results can help estimate the impact of singular modelling and design decisions (see Appendix A.3 for some example concerning system parameters), but also identify less obvious correlations. SVD could, for example, be used to identify higher-level relationships between intuitive design parameters, enabling simplification of future design studies.

Computational tools and the results they produce provide numerous opportunities for the design process. They require, however, intelligent management, e.g. of data utilized and produced, especially with further increasing computational power. 


\section{7}

Conclusions

T

HIS THESIS PRESENTED a Simulation-Based Optimization framework for an Series Hydraulic Hybrid Vehicle application, and its utilization for exploring various aspects of the design optimization. A dynamic simulation model of the hydraulic hybrid transmission was set up in Hopsan to capture and evaluate the driveability and fuel economy of a given design. The model uses a rule-based control strategy, which has been modulated to provide smoother operation than its 'bang-bang' origin. Through simultaneous Simulation-Based Optimization of component sizing and control parameters an optimization algorithm is tasked with finding the best trade-off between all design parameters considered.

The thesis in its entirety illustrates the development of the Simulation-Based Optimization framework through various stages, exploring and evaluating possibilities to achieve desired properties for the optimized design. Choices made for the framework itself are also assessed. A high volume of optimization experiments for evaluating optimization under a test case heavier than typical test functions is thereby enabled by a Linux cluster infrastructure, capitalizing on some of the simulation tool's particular features.

The work presented contributes to the research questions as follows.

\section{RQ1: How can computational tools be used to study the feasibility of HHV transmissions?}

In hydraulic hybrid transmissions, the State-of-Charge of the hydraulic accumulator determines both the reserve for the available power and for the recuperation of kinetic energy. Due to this relationship, the system needs an appropriate control strategy to guarantee driveability. Forward-facing dynamic simulation helps evaluate whether a particular system can deliver a required performance with the variable power source of the accumulator. Through simulation-based optimization, design parameters can be evaluated systematically where manual approaches require interconnected assumptions. 


\section{RQ2: What aspects of the system need to be modelled and studied in the context of Simulation-Based Optimization?}

Next to the system model itself, a forward-facing simulation model requires among other things a driver model, and for evaluating driving missions a measure quantifying that driving performance. To capture effects of SimulationBased Optimization, especially of component sizes, numerous scaling relationships, in particular for the system components, need to be included to adequately capture sizing effects.

For simultaneous component and control optimization, the control strategy needs to be simple enough to be characterized by few parameters, but at the same time guarantee satisfactory performance for driving and operation. In the context of the optimization it is relevant to identify the most important parameters to optimize. Seemingly less important parameters can, however, affect performance if not addressed appropriately.

\section{RQ3: When using complex, i.e. computationally heavy, models, how can Simulation-Based Optimization be used and improved upon?}

Simulation models capturing numerous system details and studying various relevant aspects easily become complex. For use in Simulation-Based Optimization it is therefore important to utilize well-performing, i.e. robust and 'fast', algorithms to address the optimization problem. The Simulation-Based Optimization is aided further by making use of multi-threaded computational infrastructure. Especially when an accurate solution, i.e. a global optimum, is not of the highest priority, for example due to already established uncertainties, there are optimization methods to handle the computational burden within acceptable time constraints.

\section{RQ4: How can the results obtained through Simulation-Based Optimization be analysed and used to further improve the framework?}

Solutions from numerical optimizations are extremely precise but seldom overly robust. Corresponding analyses can therefore aid in identifying the most sensitive aspects and parameters of a solution and the underlying model including its assumptions as well as the most challenging requirements. Simulation-Based Optimization can even yield improbable solutions, where an algorithm identifies unaddressed 'loopholes' in a model or problem formulation, and provide information for an iterative model development process.

Not only the design parameter values obtained, system parameters or constraint limits set are relevant to study, but also other framework aspects, including problem dimensionality, problem formulation and optimization algorithm applied. Based on these, the overall performance of the Simulation-Based Optimization framework, both computationally and with regard to the information gathered, can be developed further. 


\section{8 \\ Review of Papers}

\section{Paper I}

\section{System Parameter Study for a Light-Weight Series Hydraulic Hybrid Vehicle}

This paper illustrates the starting point for SBO considerations. The simulation model contains a simple accumulator model with an unscaled time constant and a simple torque source to emulate a diesel engine. Only the effect of the scaling of the hydraulic components on the total system mass is considered through linear functions. The supervisory control of diesel engine and pump is an SoC-based 'bang-bang' strategy, aiming to achieve constant operation of the engine at its 'sweet spot'. Due to the lack of a BSFC-map for the diesel engine, abstract energy considerations are used to estimate the efficiency of the SHHV transmission.

The baseline design is selected based on simple feasibility tests over two drive cycles (UDDS and NYCC). Variations of several control parameters are studied through single and multiple parameter sweeps, namely the engine operating points, and the SoC-pressure levels. Variation of the maximum system pressure is considered, but without its effect on component properties.

By demonstrating the complexity of improving on the baseline design manually, the paper illustrates that the framework can benefit from the use of numerical optimization to address multiple design parameters simultaneously. 


\section{Paper II}

\section{Design Study and Parameter Optimization for a Light-Weight Series Hydraulic Hybrid Vehicle}

Here, the model has been extended to gauge the diesel engine's fuel consumption based on a BSFC-map, and to consider a speed-dependent Wide Open Throttle (WOT) curve. The control of the hydraulic pump and the diesel engine has been modified to move away from a single operating point. Instead, operation along the path of least fuel consumption is targeted in transition between SoC limits, while aiming for full pump displacement without stalling the engine in doing so.

The first sets of optimization experiments are conducted using the ComplexRF algorithm, initially addressing UDDS and NYCC individually. Next, the drive cycles are considered simultaneously to move away from one deterministic drive cycle, and to provide additional implicit performance requirements. The results illustrate how the optimization algorithm converges on different solutions. The information-entropy-rate-based performance index is applied in its basic form to compare the optimization problem's complexity to that of a unimodal hump.

\section{Paper III}

\section{Aspects of Parameter Sensitivity for Series Hydraulic Hybrid Light-Weight Duty Vehicle Design}

The simulation model for this paper has been extended among other things with component scaling relationships addressing not only the impact on the system mass, but also additional component properties. The control strategies are slightly modified with the aim of reducing pump/motor displacement when the pressure level drops too fast before the diesel engine and pump recharge the system to the operating pressure range, and to modulate the SoC-limits depending on the current drive speed linearly.

The optimization addresses three standard drive cycles (UDDS, NYCC and HWFET) individually and in combinations. The optimization experiments are conducted using a remote simulation framework, which allows multiple experiments to be run in parallel. Several sensitivity aspects are studied, in the optimized parameters, otherwise constant system parameters, as well as variations in the drive cycles with regard to the order of the driving events.

Sensitivity analysis is not dealt with to its maximum extent; the considerations rather serve to illustrate that it is a useful tool for studying the optimization results and to question parametric assumptions from the modelling phase. It can help to identify both more and less important parameters, potential modelling issues, and future considerations to include in the simulation model and 
optimization problem.

\section{Paper IV}

\section{Framework for Simulation-Based Simultaneous System Opti- mization for a Series Hydraulic Hybrid Vehicle}

The paper's simulation model includes both refined and updated diesel engine and accumulator component models and updated component scaling relationships. The rule-based control strategy has been extended to reduce control signal discontinuities and improve diesel engine availability and the previous modifications have been updated so that they can be described by one design parameter, each.

The formulation of the optimization problem also includes engine startup considerations, addresses the final accumulator SoC-level and penalizes inadmissible parameter constellations as well as hydraulic system failure conditions. The optimization focuses on three standard drive cycles (UDDS, NEDC and WLTC3) which are typically used to estimate a vehicle fuel's economy. In some of the experiments, moderate maximum velocity and acceleration performance requirements are also simulated and considered to aim for designs with more robust driveability, which is evaluated over the other drive cycles.

With the minor exception of a speed-reducing gear mentioned in the following paper, this paper marks the final iteration of the SBO framework's model within the scope of this thesis.

\section{Paper V}

\section{Optimization Method Evaluation for Simulation-Based Control and Component Parameter Design of a Series Hydraulic Hybrid Vehicle}

In the SHHV model, a mismatch of diesel engine and hydraulic pump speed is addressed through a lossless gear, leading to larger pumps in the optimization results.

The focus is shifted from various test conditions for the simulated vehicle (drive cycles and performance requirements) to the optimization algorithm applied and the problem formulation in terms of optimization parameter selection. Parallel implementations of the Complex-RF algorithm and a PSO algorithm are tested, and two performance indices are adapted for the optimization problem's complex results. The inclusion of previously constant control parameters in the design space can yield improved optimization results at increased computational cost. A final sensitivity analysis illustrates, as with previous 
results, how certain, especially control-related, design parameters are fairly robust against small variations. 


\section{Appendices}

\section{A.1 Specifications of Optimization Computers}

In order to obtain representative results and to address stochastic elements of the algorithm, optimization experiments were repeated multiple times. From paper [III] on, optimizations were conducted on a Linux-based computer cluster. While these computers' performance was sufficient for sequential and parallel implementations of the Complex-RF algorithm, for the use of a populationbased method further modifications would have been required to handle the load. Instead, a desktop computer specifically set up for optimization experiments was used. For comparison, some of the computers' specifications are listed in Table A.1, and to provide a reference a standard personal laptop computer is included. To better illustrate the computers' performance, the simulation time required for the baseline model from paper [V], i.e. for simulation over the UDDS while also evaluating the simulation-based performance requirements, using the Hopsan Command Line Interface is included. 
Table A.1 Computers utilized for optimization experiments in paper [V]

\begin{tabular}{|c|c|c|c|}
\hline Computer & Use case & Specifications & $\begin{array}{l}\text { Simulation time } \\
\text { reference model }\end{array}$ \\
\hline $\begin{array}{r}\text { Cluster } \\
\text { nodes }\end{array}$ & $\begin{array}{l}\text { Complex-RF } \\
\text { and -RFP } \\
\text { optimization }\end{array}$ & $\begin{array}{l}\text { Intel }^{\circledR} \text { Core }^{\mathrm{TM}} 2 \\
\text { Duo CPU } \\
\text { E8500 } \\
\text { @ } 3.16 \mathrm{GHz} \\
\quad(2 \text { cores, } 2 \text { threads }) \\
4 \text { GB RAM } \\
\text { Ubuntu } 14.04 .4\end{array}$ & $36 \mathrm{~s}$ \\
\hline $\begin{array}{l}\text { Desktop } \\
\text { computer }\end{array}$ & PSO & $\begin{array}{l}\text { Intel }^{\circledR} \text { Xeon }{ }^{\circledR} \text { CPU } \\
\text { E5-2623 v3 } \\
@ 3.00 \mathrm{GHz} \\
\text { (4 cores, } 8 \text { threads) } \\
128 \text { GB RAM } \\
\text { Windows } 10\end{array}$ & $21 \mathrm{~s}$ \\
\hline $\begin{array}{l}\text { Laptop } \\
\text { computer }\end{array}$ & $\begin{array}{l}\text { Sensitivity } \\
\text { analysis } \\
\text { Reference }\end{array}$ & $\begin{array}{l}\text { Intel }{ }^{\circledR} \text { Core }^{\mathrm{TM}} \mathrm{CPU} \\
\text { i5- } 2410 \mathrm{M} \\
\text { @ } 2.30 \mathrm{GHz} \\
\text { (2 cores, } 4 \text { threads) } \\
4 \text { GB RAM } \\
\text { Windows } 7\end{array}$ & $36 \mathrm{~s}$ \\
\hline
\end{tabular}




\section{A.2 Component Scaling}

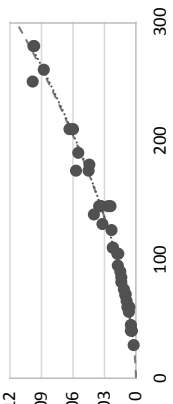

궁 :

[гшбу] е!пдиц
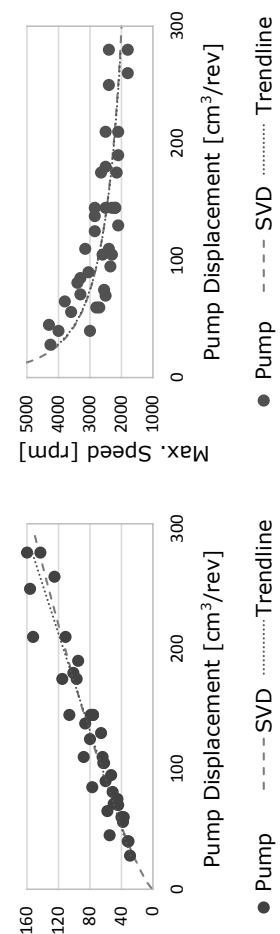

[6y] ssew
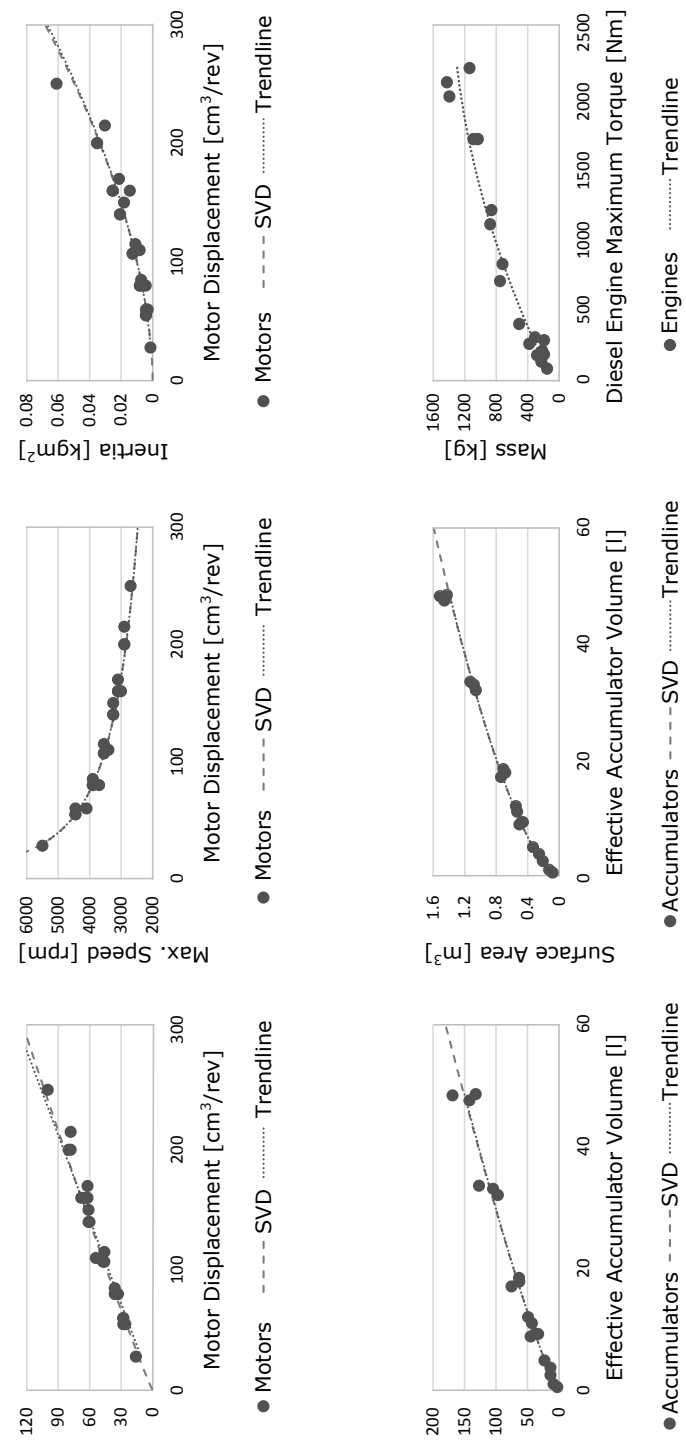

[6y] ssew

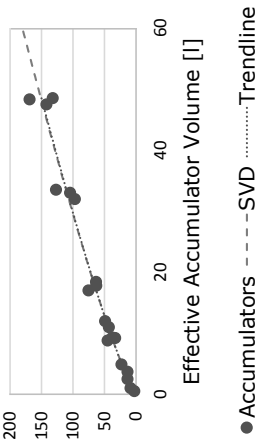

[6y] ssew

Figure A.1 Scaling relationships for main system components, including trendlines for component data, and SVD-derived relationships for the hydraulic components. In the model, the mass of the bent-axis motor is increased by 25 $\%$ to account for a more complex design of a pump/motor component. 


\section{A.3 System Parameter Sensitivities}

During modelling, numerous assumptions are made for parameters values, concerning among other things the target application, the operating conditions and component characteristics. By analysing the results obtained through optimization with respect to such parameters (here referred to as system parameters), their impact on the optimization objectives can be examined. This can give insight into potential areas of interest for further exploration, indicate limitations to for example the application addressed as well as the design problem formulation, and illustrate the range of applicability for the results obtained.

A selection of parameters is listed in Table A.2, considering wide parameter ranges.

Figure A.2 illustrates the impact of the parameter variations for an optimized design on both fuel consumption and $A R V D$, as well as the number of

Table A.2 System parameters for sensitivity considerations

\begin{tabular}{|c|c|c|}
\hline Parameter & $\begin{array}{l}\text { Default } \\
\text { Value }\end{array}$ & Parameter Values \\
\hline $\begin{array}{l}\text { Accumulator time } \\
\text { constant (pre- } \\
\text { scaling), } \tau_{a c c}\end{array}$ & $90 \mathrm{~s}$ & $90 \mathrm{~s} *\{0.5,0.75,1.0,1.25,1.5\}$ \\
\hline $\begin{array}{l}\text { Start-up fuel } \\
\text { consumption, } \\
F C_{\text {start }, \mathrm{ICE}}\end{array}$ & $F C_{\text {start }, 0}{ }^{\mathrm{a}}$ & $\begin{array}{l}F C_{\text {start }, 0} *\{0.25,0.5,0.75,1.0, \ldots \\
1.25,1.5,1.75,2\}\end{array}$ \\
\hline $\begin{array}{l}\text { Engine start-up } \\
\text { time, } t_{\text {start }, \mathrm{ICE}}\end{array}$ & $0.5 \mathrm{~s}$ & $0.5 \mathrm{~s} *\{0.5,0.75,1.0,1.25,1.5\}$ \\
\hline $\begin{array}{l}\text { Effective front } \\
\text { area, } c_{d} A\end{array}$ & $1.3 \mathrm{~m}^{2}$ & $1.3 \mathrm{~m}^{2} *\{0.5,0.75,1.0,1.25,1.5\}$ \\
\hline $\begin{array}{l}\text { Rolling resistance } \\
\text { coeffcient, } c_{f r}\end{array}$ & 0.02 & $0.02 *\{0.25,0.5,0.75,1.0,1.25,1.5\}$ \\
\hline $\begin{array}{l}\text { Ambient temperature, } \\
T_{a m b}\end{array}$ & $298.15 \mathrm{~K}$ & $\begin{array}{l}\{263.15,273.15,283.215,293.15, \ldots \\
\quad 303.15\} \mathrm{K}\end{array}$ \\
\hline $\begin{array}{l}\text { Break frequencies for } \\
\text { hydraulic machines' } \\
\text { dynamics, } \omega_{p}, \omega_{p m}\end{array}$ & $50 \mathrm{rad} / \mathrm{s}$ & $\{10,25,50,75,100\} \mathrm{rad} / \mathrm{s}$ \\
\hline $\begin{array}{l}\text { Hydraulic machines' } \\
\text { efficiencies, } \eta_{v o l, p}, \\
\eta_{h m, p}, \eta_{v o l, p m}, \\
\eta_{h m, p m}\end{array}$ & variable & $\{0.9,0.925,0.95,0.975,1.0\}$ \\
\hline
\end{tabular}

${ }^{\mathrm{a}}$ By default, the fuel consumption at engine start-up is assumed to be equivalent to that of $10 \mathrm{~s}$ idling operation [103]. 

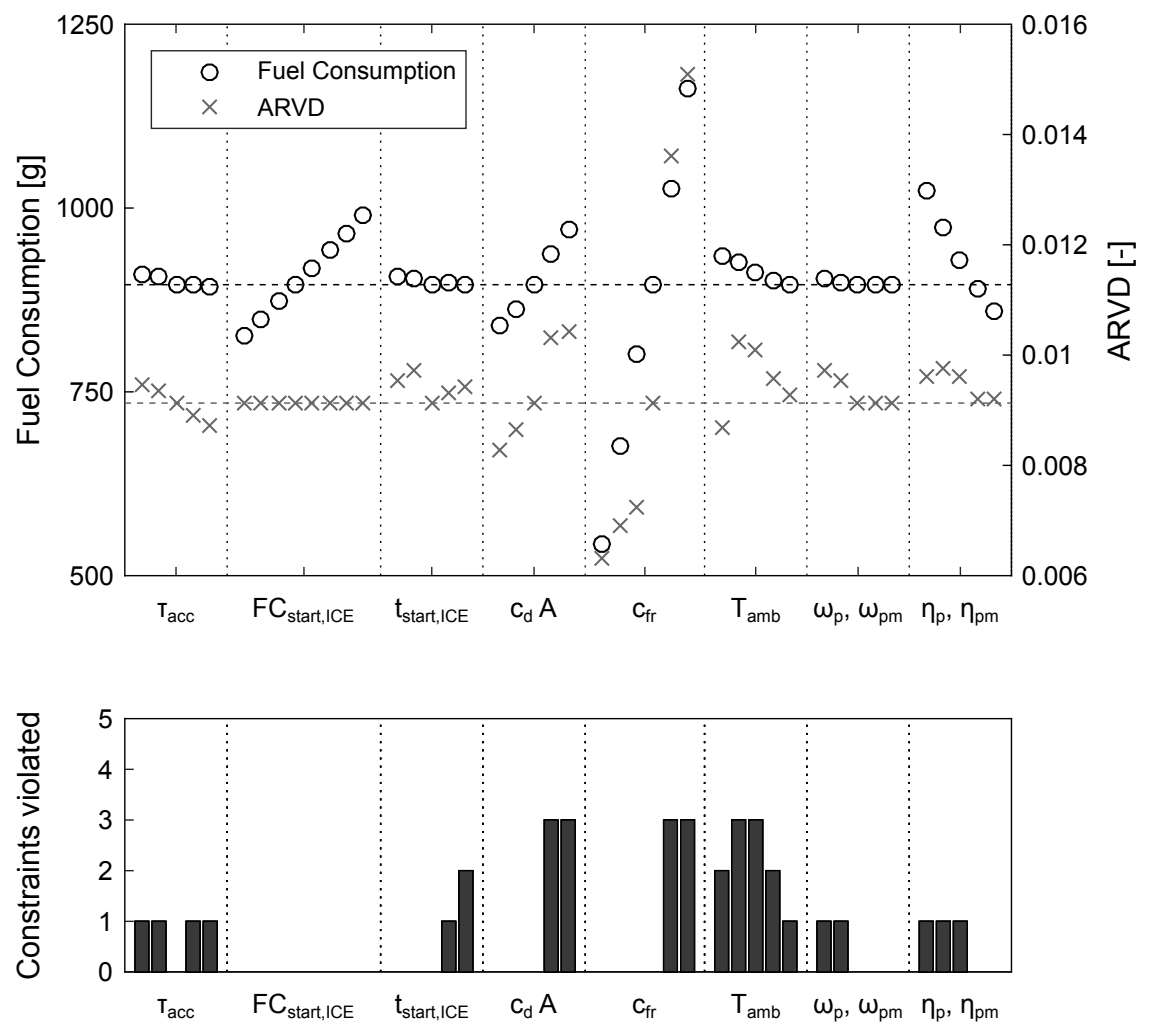

Figure A.2 Sensitivity of fuel consumption and ARVD to system parameter variation for best design from nine parameter baseline optimization (dashed lines represent original design's fuel consumption and ARVD). Also indicated is if any and how many constraints are violated by the variation.

constraints violated in each case. The sensitivity, in particular in constraints, indicates that these have a considerable impact on the solution converged upon during the optimization. 


\section{Bibliography}

[1] S. Baseley, C. Ehret, E. Greif, and M.G. Kliffken. "Hydraulic Hybrid Systems for Commercial Vehicles". In: Proceedings of the Commercial Vehicle Engineering Congress and Exhibition. Rosemont, IL, USA, 2007.

[2] L. Guzzella and A. Sciarretta. Vehicle Propulsion Systems. Berlin/Heidelberg/New York: Springer, 2005.

[3] P. Krus. "Simulation Based Optimisation for System Design". In: Proceedings of the International Conference on Engineering Design. Stockholm, Sweden, 2003.

[4] Y. Carson and A. Maria. "Simulation Optimization: Methods and Applications". In: Proceedings of the 1997 Winter Simulation Conference. Atlanta, GA, USA, 1997.

[5] L.V. Larsson. "Control Aspects of Complex Hydromechanical Transmissions with a Focus on Displacement Control". Licentiate thesis. Linköping University, Linköping, Sweden, 2017.

[6] SISO Generic Methodology for Verification and Validation Product Development Group. Generic Methodology for Verification and Validation $(G M-V V)$ to Support Acceptance of Models, Simulations, and Data. Tech. rep. SISO-GUIDE-00X.1-201X-DRAFT-V1.2.3. Simulation Interoperability Standards Organization (SISO), 2010.

[7] N.P. Suh. The Principles of Design. New York/Oxford: Oxford University Press, 1990.

[8] J. Nyman and K.-E. Rydberg. "Energy Saving Lifting Hydraulic Systems". In: Proceedings of the Seventh Scandinavian International Conference on Fluid Power. Linköping, Sweden, 2001.

[9] G. Vael, S. Eggenkamp, and P. Achten. "The E-Hydrid". In: Proceedings of The Twelfth Scandinavian International Conference on Fluid Power. Tampere, Finland, 2011. 
[10] M. Egawa and H. Kawasaki. "Study of Electro-Hydraulic Energy Saving System (EHESS) for Construction Machinery". In: Proceedings of The Twelfth Scandinavian International Conference on Fluid Power. Tampere, Finland, 2011.

[11] X. Lin, A. Ivanco, and Z. Filipi. "Optimization of Rule-Based Control Strategy for a Hydraulic-Electric Hybrid Light Urban Vehicle Based on Dynamic Programming". In: SAE International Journal of Alternative Powertrains 1.1 (2012), pp. 249-259.

[12] P. Thiebes. "Hybridantriebe für mobile Arbeitsmachinen. Grundlegende Erkenntnisse und Zusammenhänge, Vorstellung einer Methodik zur Unterstützung des Entwicklungsprozesses und deren Validierung am Beispiel einer Forstmaschine". Dissertation. Karlsruhe Institute of Technology, Karlsruhe, Germany, 2011.

[13] K.A. Stelson, J.J. Meyer, A.G. Alleyne, and B. Hencey. "Optimization of a Passenger Hydraulic Hybrid Vehicle to improve Fuel Economy". In: Proceedings of the 7th JFPS International Symposium on Fluid Power, Toyama, Japan, 2008.

[14] M. Erkkilä, F. Bauer, and D. Feld. "Universal Energy Storage and Recovery System - A Novel Approach for Hydraulic Hybrid". In: Proceedings of The 13th Scandinavian International Conference on Fluid Power. Linköping, Sweden, 2013.

[15] A. Pourmovahed. "Vehicle Propulsion Systems with Hydraulic Energy Storage: a Literature Survey". In: International Journal of Vehicle Design 12.4 (1991), pp. 378-403.

[16] J. Stecki and P. Matheson. "Advances in Automotive Hydraulic Hybrid Drives". In: Proceedings of the 6th JFPS International Symposium on Fluid Power. Tsukuba, Japan, 2005.

[17] H.P. Willumeit and B. Benneter. "Hydro-Bus - a City Bus with BrakingRecovery System". In: Proceedings of the 19th International Fisita Congress. Melbourne, Australia, 1982.

[18] D. Scott and J. Yamaguchi. "Regenerative Braking for Buses Gives Big Fuel Saving". In: Automotive Engineering 92.10 (1984), pp. 95-99.

[19] C. Hugosson. "Cumulo Hydrostatic Drive - a Vehicle Drive with Secondary Control". In: Proceedings of the Third Scandinavian International Conference on Fluid Power. Linköping, Sweden, 1993.

[20] P. Buchwald, G. Christensen, H. Larsen, and P.S. Pedersen. "Improvement of Citybus Fuel Economy Using a Hydraulic Hybrid Propulsion System - A Theoretical and Experimental Study". In: Proceedings of the SAE Congress and Exposition. Detroit, MI, USA, 1979. 
[21] A.M. Riviera. "Hydraulic Accumulator Technology Boosts Transit Bus Fuel Economy". In: Proceedings of the SAE International Congress and Exposition. Detroit, MI, USA, 1983.

[22] N. Nakazawa, Y. Kono, E. Takao, and N. Takeda. "Development of a Braking Energy Regeneration System for City Buses". In: Proceedings of the Truck and Bus Meeting and Exposition. Dearborn, MI, USA, 1987.

[23] S. Tollefson, N.H. Beachley, and F.J. Fronczak. "Studies of an Accumulator Energy-Storage Automobile Design with a Single Pump/Motor Unit". In: Proceedings of the SAE Passenger Car Meeting \& Exposition. Dearborn, MI, USA, 1985.

[24] P. Wu, N. Luo, F.J. Fronczak, and N.H. Beachley. "Fuel Economy and Operating Characteristics of a Hydropneumatic Energy Storage Automobile". In: Proceedings of the SAE Passenger Car Meeting. Dearborn, MI, USA, 1985.

[25] R.P. Kepner. "Hydraulic Power Assist - A Demonstration of Hydraulic Hybrid Vehicle Regenerative Braking in a Road Vehicle Application". In: Proceedings of the International Truck and Bus Meeting and Exhibition. Detroit, MI, USA, 2002.

[26] United States Environmental Protection Agency. Hydraulic Hybrid Research: Demonstrator Vehicles. Online: https://archive.epa.gov/otaq/technology/web/html/demonstration-vehicles.html; last accessed 201802-18. 2016.

[27] B. Wu, C.-C. Lin, Z. Filipi, H. Peng, and D. Assanis. "Optimization of Power Management Strategies for a Hydraulic Hybrid Medium Truck". In: Proceedings of the 2002 Advanced Vehicle Control Conference. Hiroshima, Japan, 2002.

[28] Z. Filipi, L. Louca, B. Daran, C.-C. Lin, U. Yildir, B. Wu, M. Kokkolaras, D. Assanis, H. Peng, P. Papalambros, J. Stein, D. Szkubiel, and R. Chapp. "Combined Optimisation of Design and Power Management of the Hydraulic Hybrid Propulsion System for the $6 \times 6 \mathrm{Me}-$ dium Truck". In: International Journal of Heavy Vehicle Systems 11.3/4 (2004), pp. 372-402.

[29] B. Surampudi, A. Nedungadi, G. Ostrowski, A. Montemayor, and H. Gruenewald. "Design and Control Considerations for a Series Heavy Duty Hybrid Hydraulic Vehicle". In: Proceedings of the SAE 2009 Powertrains Fuels and Lubricants Meeting. San Diego, CA, USA, 2009.

[30] K. Pettersson, K. Heybroek, P. Mattsson, and P. Krus. "A Novel Hydromechanical Hybrid Motion System for Construction Machines". In: International Journal of Fluid Power 18.1 (2017), pp. 17-28.

[31] K. Heybroek. "On Energy Efficient Mobile Hydraulic Systems. With Focus on Linear Actuation". Dissertation. Linköping University, Linköping, Sweden, 2017. 
[32] L. Serrao, G. Ornella, G. Burgio, and E. Cosoli. "Development and Testing of a Hydraulic Hybrid Concept for Off-Highway Vehicles". In: Proceedings of the SAE 2013 Commercial Vehicle Engineering Congress. Rosemont, IL, USA, 2013.

[33] T. Schaep, W. Marquis-Favre, E. Bideaux, E. Noppe, P. Rodot, J.-C. Bernigaud, and V. Langlois. "Combined Kinetic and Potential Energy Recovery Solution Applied to a Reach Stacker". In: Proceedings of the 9th FPNI Ph.D. Symposium on Fluid Power. Florianópolis, SC, Brazil, 2016.

[34] H. Hänninen. "Reducing Energy Consumption of Reach Truck Utilizing Hydraulic Energy Recovery Systems". Dissertation. Aalto University, Espoo, Finland, 2016.

[35] J. Kargul, A. Moskalik, K. Newman, D. Barba, and J. Rockwell. "Design and Demonstration of EPA's Integrated Drive Module for Commercial Series Hydraulic Hybrid Trucks and Buses". In: SAE International Journal of Commercial Vehicles 8.2 (2015), pp. 549-567.

[36] S. Tikkanen, M.G. Kliffken, C. Ehret, and S. Baseley. "Hydraulic Hybrid Systems for Working Machines and Commercial Vehicles". In: Proceedings of the 51st National Conference on Fluid Power. Las Vegas, NV, USA, 2008.

[37] PSA Groupe. Hybrid Air: An Innovative Full-Hybrid Petrol Solution for the Car of the Future. Online: https://www.groupe-psa.com/en/newsroom/automotive-innovation/hybrid-air/; last accessed 2018-02-18. 2013.

[38] S. Shelton. PSA Shelves Hybrid Air Project While Awaiting New Partners. Online: http://www.hybridcars.com/psa-shelves-hybrid-airproject-while-awaiting-new-partners/; last accessed 2018-02-18. 2015.

[39] Eaton Corporation. Hydraulic Launch Assist ${ }^{T M}$ Refuse Truck. Online: http://www.eaton.com/ecm/groups/public/@pub/@eaton/@hyd/ documents/content/pll_1006.pdf; last accessed 2018-02-18. 2009.

[40] J. Park and D. Lockridge. Eaton Drops Hydraulic Hybrid System. Online: http://www.truckinginfo.com/channel/aftermarket/news/story/2013/09/eaton-drops-hydraulic-hybrid-system.aspx?prestitial=1; last accessed 2018-02-18. 2013.

[41] B.L. Van Batavia. "Hydraulic Hybrid Vehicle Energy Management System". In: Proceedings of the Powertrains, Fuels and Lubricants Meeting. Florence, Italy, 2009.

[42] L.E. Hall. How Hydraulic Hybrids Save Tons of Fuel Where It's Needed Most. Online: http://www.hybridcars.com/how-hydraulic-hybrids-savetons-of-fuel-and-emissions-where-its-needed-most/; last accessed 201802-18. 2017. 
[43] A. Johansson and J.-C. Ossyra. "Hydraulic Hybrid Transmission Design Considerations for Optimal Customer Satisfaction". In: Proceedings of the 7th International Fluid Power Conference. Aachen, Germany, 2010.

[44] J. Taylor, W. Rampen, A. Robertson, and N. Caldwell. "Digital Displacement ${ }^{\circledR}$ Hydraulic Hybrids. Parallel Hybrid Drives for Commercial Vehicles". In: Proceedings of the JSAE Annual Congress. Yokohama, Japan, 2011.

[45] J. Taylor, W. Rampen, D. Abrahams, and A. Latham. "Demonstration of a Digital Displacement ${ }^{\circledR}$ Hydraulic Hybrid Bus ... a globally affordable way of saving fuel". In: Proceedings of the JSAE Annual Congress. Yokohama, Japan, 2015.

[46] P. Achten, G. Vael, M.I. Sokar, and T. Kohmäscher. "Design and Fuel Economy of a Series Hydraulic Hybrid Vehicle". In: Proceedings of the 7th JFPS International Symposium on Fluid Power. Toyama, Japan, 2008.

[47] D.R. Kapellen, F. Jamzadeh, A.A. Frank, and S. Wang. "Analysis of Energy-Storage Concepts for Refuse Collection Trucks". In: Proceedings of the SAE International Congress $\&$ Exhibition. Detroit, MI, USA, 1984.

[48] A. Sciarretta and L. Guzzella. "Control of Hybrid Electric Vehicles". In: IEEE Control Systems Magazine 27.2 (2007), pp. 60-70.

[49] M.A. Karbaschian and D. Söffker. "Review and Comparison of Power Management Approaches for Hybrid Vehicles with Focus on Hydraulic Drives". In: Energies 7.6 (2014), pp. 3512-3536.

[50] Y.J. Kim. "Integrated Modeling and Hardware-in-the-loop Study for Systematic Evaluation of Hydraulic Hybrid Propulsion Options". Dissertation. University of Michigan, Ann Arbor, MI, USA, 2008.

[51] S. Molla and B. Ayalew. "Power Management Strategies for a Series Hydraulic Hybrid Drivetrain". In: International Journal of Powertrains 1.1 (2011), pp. 93-116.

[52] T.O. Deppen, A.G. Alleyne, J.J. Meyer, and K.A. Stelson. "Comparative Study of Energy Management Strategies for Hydraulic Hybrids". In: Journal of Dynamic Systems, Measurement, and Control 137.4 (2015), pp. 041002-1 - 041002-11.

[53] K. Uebel. "Conceptual Design of Complex Hydromechanical Transmissions". Dissertation. Linköping University, Linköping, Sweden, 2017.

[54] J.D. Van de Ven. "Constant Pressure Hydraulic Energy Storage through a Variable Area Piston Hydraulic Accumulator". In: Applied Energy 105 (2013), pp. 262-270. 
[55] R. Kumar and M. Ivantysynova. "An Instantaneous Optimization Based Power Management Strategy to Reduce Fuel Consumption in Hydraulic Hybrids". In: International Journal of Fluid Power 12.2 (2011), pp. 1525 .

[56] M. Sprengel and M. Ivantysynova. "Neural Network Based Power Management of Hydraulic Hybrid Vehicles". In: International Journal of Fluid Power 18.2 (2017), pp. 79-91.

[57] J.A. Reyer. "Combined Embodiment Design and Control Optimization: Effects of Cross-Disciplinary Coupling". Dissertation. University of Michigan, Ann Arbor, MI, USA, 2000.

[58] H.K. Fathy, J.A. Reyer, P.Y. Papalambros, and A.G. Ulsoy. "On the Coupling between the Plant and Controller Optimization Problems". In: Proceedings of the American Control Conference. Arlington, VA, USA, 2001.

[59] E. Silvas, T. Hofman, N. Murgovski, P. Etman, and M. Steinbuch. "Review of Optimization Strategies for System-Level Design in Hybrid Electric Vehicles". In: IEEE Transactions on Vehicular Technology 66.1 (2017), pp. 57-70.

[60] H. Sun. "Multi-Objective Optimization for Hydraulic Hybrid Vehicle based on Adaptive Simulated Annealing Genetic Algorithm". In: Engineering Applications of Artificial Intelligence 23 (2010), pp. 27-33.

[61] T. Liu and X. Ju. "Parameter Optimization of Hydraulic Hybrid Vehicle Based on Genetic Algorithm". In: Applied Mechanics and Materials 2932 (2010), pp. 1079-1084.

[62] B. Moulik, M.A. Karbaschian, and D. Söffker. "Size and Parameter Adjustment of a Hybrid Hydraulic Powertrain Using a Global MultiObjective Optimization Algorithm". In: Proceedings of the 2013 IEEE Vehicle Power and Propulsion Conference. Beijing, China, 2013.

[63] M.A. Karbaschian. "Improving System Design and Power Management for Hybrid Hydraulic Vehicles Minimizing Fuel Consumption”. Dissertation. University of Duisburg-Essen, Duisburg, Germany, 2014.

[64] K.L. Cheong, P.Y. Li, and T.R. Chase. "Optimal Design of Power-Split Transmissions for Hydraulic Hybrid Passenger Vehicles". In: Proceedings of the 2011 American Control Conference. San Francisco, CA, USA, 2011.

[65] Z. Du, K.L. Cheong, P.Y. Li, and T.R. Chase. "Fuel Economy Comparison of Series, Parallel and HMT Hydraulic Hybrid Architectures". In: Proceedings of the 2013 American Control Conference, Washington, DC, USA, 2013. 
[66] F. Mensing and P.Y. Li. "Sizing and Optimal Operation of a Power Split Hydraulic Hybrid Drive Train". In: Proceedings of the 52nd National Conference on Fluid Power. Las Vegas, NV, USA, 2011.

[67] C.-T. Li and H. Peng. "Optimal Configuration Design for Hydraulic Split Hybrid Vehicles". In: Proceedings of the 2010 American Control Conference. Baltimore, MD, USA, 2010.

[68] M.I. Ramdan. "Optimal Design of a Hydro-Mechanical Transmission Power Split Hybrid Hydraulic Bus". Dissertation. University of Minnesota, Minneapolis, MN, USA, 2013.

[69] K.B. Wipke, M.R. Cuddy, and S.D. Burch. "ADVISOR 2.1: A UserFriendly Advanced Powertrain Simulation Using a Combined Backward/Forward Approach". In: IEEE Transactions on Vehicular Technology 48.6 (1999), pp. 1751-1761.

[70] G. Mohan, F. Assadian, and S. Longo. "Comparative Analysis of Forward-Facing Models vs Backward-Facing Models in Powertrain Component Sizing". In: Proceedings of the IET 4th Hybrid and Electric Vehicles Conference. London, UK, 2013.

[71] MathWorks. Simulink. Online: https://www.mathworks.com/products/simulink.html; last accessed 2018-02-18.

[72] M.R. Cuddy and K.B. Wipke. "Analysis of the Fuel Economy Benefit of Drivetrain Hybridization". In: Proceedings of the International Congress E Exposition. Detroit, MI, USA, 1997.

[73] T. Markel, A. Brooker, T. Hendricks, V. Johnson, K. Kelly, B. Kramer, M. O'Keefe, S. Sprik, and K. Wipke. "ADVISOR: A Systems Analysis Tool for Advanced Vehicle Modeling". In: Journal of Power Sources 110 (2002), pp. 255-266.

[74] National Renewable Energy Laboratory. ADVISOR Advanced Vehicle Simulator. Online: http://adv-vehicle-sim.sourceforge.net/; last accessed 2018-02-18. 2003.

[75] Siemens PLM Software. Simcenter Amesim. Online: https://www.plm.automation.siemens.com/en/products/lms/imagine-lab/amesim/; last accessed 2018-02-18.

[76] M. Axin, R. Braun, A. Dell'Amico, B. Eriksson, P. Nordin, K. Pettersson, I. Staack, and P. Krus. "Next Generation Simulation Software using Transmission Line Elements". In: Proceedings of Fluid Power and Motion Control. Bath, UK, 2010.

[77] B. Eriksson, P. Nordin, and P. Krus. "Hopsan NG, A C++ Implementation using the TLM Simulation Technique". In: Proceedings of the 51st Conference on Simulation and Modelling. Oulu, Finland, 2010. 
[78] D.M. Auslander. "Distributed System Simulation With Bilateral DelayLine Models". In: Journal of Basic Engineering 90.2 (1968), pp. 195200 .

[79] P. Krus, A. Jansson, J.-O. Palmberg, and K. Weddfelt. "Distributed Simulation of Hydromechanical Systems". In: Proceedings of the Third Bath International Fluid Power Workshop. Bath, UK, 1990.

[80] F.J. Fronczak and N.H. Beachley. "An Integrated Hydraulic Drive Train System for Automobiles". In: Proceedings of the 8th International Symposium on Fluid Power. Birmingham, UK, 1988.

[81] M. Cross and M. Ivantysynova. "Practical Considerations for Pump/Motor Selection in Hybrid Hydraulic Vehicles". In: Proceedings of the 52nd National Conference on Fluid Power. Las Vegas, NV, USA, 2011.

[82] K.-E. Rydberg. "On Performance Optimization and Digital Control of Hydrostatic Drives for Vehicle Applications". Dissertation. Linköping University, Linköping, Sweden, 1983.

[83] D.R. Otis and A. Pourmovahed. "An Algorithm for Computing Nonflow Gas Processes in Gas Springs and Hydropneumatic Accumulators". In: Journal of Dynamic Systems, Measurement, and Control 107.3 (1985), pp. 93-96.

[84] M. Sprengel and M. Ivantysynova. "Investigation and Energetic Analysis of a Novel Hydraulic Hybrid Architecture for On-Road Vehicles". In: Proceedings of the 13th Scandinavian International Conference on Fluid Power. Linköping, Sweden, 2013.

[85] H.B. Hansen and P.W. Rasmussen. "Modeling Hydraulic Accumulators for use in Wind Turbines". In: Proceedings of the 13th Scandinavian International Conference on Fluid Power. Linköping, Sweden, 2013.

[86] G. Soave. "Equilibrium Constants from a Modified Redlich-Kwong Equation of State". In: Chemical Engineering Science 27 (1972), pp. 1197-1203.

[87] R.T. Ellington, O.T. Bloomer, B.E. Eakin, and D.C. Gami. "Thermodynamic Properties of Methane-Nitrogen Mixtures". In: Symposium on Thermal Properties. Purdue, IN, USA, 1959.

[88] S.-C. Tsai and M.R. Goyal. "Dynamic Turbocharged Diesel Engine Model for Control Analysis and Design". In: Proceedings of the International Congress and Exposition. Detroit, MI, USA, 1986.

[89] D.N. Assanis and J.B. Heywood. "Development and Use of a Computer Simulation of the Turbocompounded Diesel System for Engine Performance and Component Heat Transfer Studies". In: Proceedings of the International Congress and Exposition. Detroit, MI, USA, 1986. 
[90] J. Wahlström and L. Eriksson. "Modelling Diesel Engines with a Variable-Geometry Turbocharger and Exhaust Gas Recirculation by Optimization of Model Parameters for Capturing Non-Linear System Dynamics". In: Proceedings of the Institution of Mechanical Engineers, Part D: Journal of Automobile Engineering 225.7 (2011), pp. 960-986.

[91] P. Krus. "Design Space Configuration for Minimizing Design Information Entropy". In: Proceedings of the International Conference on Research into Design. Bangalore, India, 2015.

[92] M. Sannelius and J.-O. Palmberg. "Conceptual Design of Complex Hydrostatic Transmissions". In: Proceedings of the 7th Bath International Fluid Power Workshop on Innovations in Fluid Power. Bath, UK, 1994.

[93] K. Pettersson and P. Krus. "Design Optimization of Complex Hydromechanical Transmissions". In: Journal of Mechanical Design 135.9 (2013), pp. 091005-1 - 091005-9.

[94] R. Schulz. "Simulation hydraulischer Energiespeicher". In: Ölhydraulik und Pneumatik 23.10 (1979), pp. 729-731.

[95] K.-E. Rydberg. "Gas-Charged Accumulators as Energy Storage Devices in Hydrostatic Drives". In: Proceedings of the IASTED Symposium Energy and Environmental Systems. Nice, France, 1984.

[96] D. Assanis, G. Delagrammatikas, R. Fellini, Z. Filipi, N. Liedtke, N. Michelena, P. Papalambros, D. Reyes, D. Rosenbaum, A. Sales, and M. Sasena. "Optimization Approach to Hybrid Electric Propulsion System Design". In: Journal of Mechanics of Structures and Machines 27.4 (1999), pp. 393-421.

[97] P. Brabec, M. Maly, and R. Vozenilek. "Experimental Determination of a Powertrain's Inertia Ellipsoid". In: Bulletin of Applied Mechanics 7.25 (2011), pp. 15-20.

[98] Y.J. Kim and Z. Filipi. "Series Hydraulic Hybrid Propulsion for a Light Truck - Optimizing the Thermostatic Power Management". In: Proceedings of the 8th International Conference on Engines for Automobiles. Capri/Naples, Italy, 2007.

[99] E.R. Colburn and J.R. Rinderle. "Design Relations". In: Proceedings of the Second ASME Design Theory and Methodology Conference. Chicago, IL, USA, 1990.

[100] P. Nordin, R. Braun, and P. Krus. "Job-Scheduling of Distributed Simulation-Based Optimization with Support for Multi-Level Parallelism". In: Proceedings of the 56th Conference on Simulation and Modelling. Linköping, Sweden, 2015.

[101] J. Andersson. "Multiobjective Optimization in Engineering Design. Applications to Fluid Power Systems". Dissertation. Linköping University, Linköping, Sweden, 2001. 
[102] J. Branke, K. Deb, K. Miettinen, and R. Slowinski. "Preface". In: ed. by J. Branke, K. Deb, K. Miettinen, and R. Slowinski. Berlin/Heidelberg: Springer, 2008, pp. V-XII.

[103] E. Burgess, M. Peffers, and I. Silverman. Idling Gets You Nowhere. The Health, Environmental and Economic Impacts of Engine Idling in New York City. Tech. rep. Environmental Defense Fund, 2009.

[104] M.J. Box. "A New Method of Constrained Optimization and a Comparison with Other Methods". In: The Computer Journal 8.1 (1965), pp. $42-52$.

[105] J.A. Guin. "Modification of the Complex Method of Constrained Optimization". In: The Computer Journal 10.4 (1968), pp. 416-417.

[106] P. Krus and J. Andersson. "Optimizing Optimization for Design Optimization". In: Proceedings of the ASME 2003 Design Engineering Technical Conferences and Computers and Information in Engineering Conference. Chicago, IL, USA, 2003.

[107] M. Pettersson and J. Ölvander. "Drive Train Optimization for Industrial Robots". In: IEEE Transactions on Robotics 25.6 (2009), pp. 1419-1424.

[108] J. Ölvander and P. Krus. "Optimizing the Optimization - A Method for Comparison of Optimization Algorithms". In: Proceedings of the 47 th AIAA/ASME/ASCE/AHS/ASC Structures, Structural Dynamics, and Materials Conference, Structures, Structural Dynamics, and Materials Conference. Newport, RI, USA, 2006.

[109] P.L. Matheson and J.S. Stecki. "Optimisation of a Hybrid DieselHydraulic Automotive Powertrain using ADVISOR, Matlab and Simulink". In: Australian Journal of Mechanical Engineering 2.1 (2005), pp. $43-50$.

[110] R.A. Fellini. "Derivative-Free and Global Search Optimization Algorithms in an Object-Oriented Design Framework". Master's thesis. University of Michigan, Ann Arbor, MI, USA, 1998.

[111] R. Braun and P. Krus. "Parallel Implementations of the Complex-RF Algorithm". In: Engineering Optimization 49.9 (2017), pp. 1558-1572.

[112] P.-M. Olsson. "Methods for Network Optimization and Parallel Derivative-free Optimization". Dissertation. Linköping University, Linköping, Sweden, 2014.

[113] J. Persson. "Efficient Optimization of Complex Products. A Simulation and Surrogate Model Based Approach". Dissertation. Linköping University, Linköping, Sweden, 2015.

[114] G.V. Reklaitis, A. Ravindran, and K.M. Ragsdell. Engineering Optimization. New York, NY, USA: John Wiley \& Sons, 1983. 
[115] P. Krus and J. Ölvander. "Performance Index and Meta-Optimization of a Direct Search Optimization Method". In: Engineering Optimization 45.10 (2013), pp. 1167-1185.

[116] J.A. Persson and J. Ölvander. "Optimization of the Complex-RFM Optimization Algorithm". In: Optimization and Engineering 16 (2015), pp. $27-48$.

[117] C.E. Shannon. "A Mathematical Theory of Communication". In: The Bell System Technical Journal 27 (July 1948), pp. 379-423, 623-656.

[118] T.J. Barlow, S. Latham, I.S. McCrae, and P.G. Boulter. A Reference Book of Driving Cycles for Use in the Measurements of Road Vehicle Emissions. Project Report PPR354. Department for Transport, UK, 2009.

[119] C. Scholler. "Modellgestützter Vergleich hydraulischer Konzepte zur Reduzierung des Energiebedarfs mobiler Arbeitsmaschinen unter Berücksichtigung variabler, kundenspezifischer Nutzungsprofile am Beispiel eines Baggers". Dissertation. University of Kaiserslautern, Kaiserslautern, Germany, 2015.

[120] P. Nyberg. "Evaluation, Generation, and Transformation of Driving Cycles". Dissertation. Linköping University, Linköping, Sweden, 2015.

[121] J. Kargul, A. Moskalik, D. Barba, K. Newman, and P. Dekraker. "Estimating GHG Reduction from Combinations of Current Best-Available and Future Powertrain and Vehicle Technologies for a Midsized Car Using EPA's ALPHA Model". In: Proceedings of the SAE 2016 World Congress 85 Exhibition. Detroit, MI, USA, 2016.

[122] S. Tikkanen, E. Koskela, V. Ahola, and K. Huhtala. "Emission Reduction of Mobile Machines by Hydraulic Hybrid". In: Proceedings of the 15th Scandinavian International Conference on Fluid Power. Linköping, Sweden, 2017.

[123] S. Mutschler. "Economic Evaluation of Hydrostatic Drive Train Concepts for Mobile Machinery". In: Proceedings of the 6th International Fluid Power Conference. Dresden, Germany, 2008.

[124] M. Woon, S. Nakra, A. Ivanco, and Z. Filipi. "Series Hydraulic Hybrid System for a Passenger Car: Design, Integration and Packaging Study". In: Proceedings of the SAE 2012 World Congress 85 Exhibition. Detroit, MI, USA, 2012. 


\section{Appended Papers}

The papers associated with this thesis have been removed for copyright reasons. For more details about these see:

http://urn.kb.se/resolve?urn=urn:nbn:se:liu:diva-145387 
Stay hungry. Stay foolish.

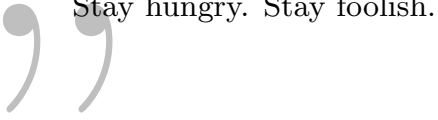

Whole Earth Catalogue (1971) quoted by S.P. Jobs (2005) quoted by W.A. Cools (ca. 2011) 